\title{
Population Trends and Problems of Public Health
}

\author{
GEORGE ST.J. PERROTT and \\ DOROTHY F. HOLLAND
}

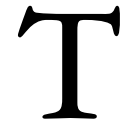

HE SCOPE AND EMPhasis OF A public HEALTh program are necessarily influenced by the changing characteristics of the population it serves. The rate of population growth affects long-range planning of community health and medical facilities. Alterations in age composition, internal migration of racial or industrial groups, changes in population density and urban-rural movement require current adaptation of the health program to solve the new problems thus created. Among the various characteristics of recent population trends, aging of the population is one of the most fundamental in its bearing on national health. The social and economic effects of an aging population have long been recognized. Dr. Louis I. Dublin appraised the problem of old age in some detail in 1926, when the provision of economic security for the aged was the dominant theme of contemporary discussion. ${ }^{1}$ The passage of the Social Security Act in 1935 represented the fruits of the efforts of this early period.

Adjustment of national policy with respect to the health problems associated with aging of the population has been slower in development. Under the terms of the Social Security Act, a limited expansion of activities designed to promote the health of older adults-control of cancer and pneumonia, and industrial hygiene services- has been made

This paper was presented at the Eighteenth Annual Conference of the Milbank Memorial Fund, April 2-3, 1940.

The Milbank Quarterly, Vol. 83, No. 4, 2005 (pp. 569-608)

(c) 2005 Milbank Memorial Fund. Published by Blackwell Publishing.

Reprinted from The Milbank Memorial Fund Quarterly, Vol. 18, No. 4, 1940 (pp. 359-92). Style and usage are unchanged. 
possible in the cooperating States. However, the Act makes no provision for the solution of such fundamental problems as invalidity insurance and medical care of the aged. During the past five years, the health aspects of old age have received increasing attention in the discussions of public health administrators. It therefore seems appropriate to resurvey this general problem, and to consider, in particular, the nature of future trends in mortality, morbidity, and the receipt of medical care which may be expected solely as a result of changing age structure of the population.

\section{The Effect on the Death Rate}

The effect of a declining proportion of children and an increasing proportion of "elders" on the future trend of the death rate may be readily predicated from the characteristics of age variation in mortality, which are generally familiar. The period of infancy is characterized by a large proportion of fatally terminating illnesses. Following the high mortality of the first year, the death rate declines rapidly in the succeeding years of early childhood, and the rate among children 5 to 14 years of age is lower than in any period of life. The age curve of mortality remains at a relatively low level in youth and the young adult ages. During the period of middle age, a marked upward trend in the death rate becomes apparent, and the increase thereafter is progressive. The sharp downward trend in the death rate following infancy and the rapid rise which occurs during middle and old age are the most pronounced characteristics of age variation in mortality. The mortality rate in infancy and early childhood has shown a marked reduction in the present century, while the rate at the advanced ages has remained practically unchanged. Thus, the death rate at the older ages has shown an increasing relative excess over the rate in the early years of life. Furthermore, aging of the population has increased the number of older persons exposed to the chance of death. Deaths of persons 45 years of age and over constituted over two-thirds of all deaths in this country in 1935; in the Registration States of 1900, the proportion was approximately two-fifths.

It thus results that the diseases which at present are the leading causes of death in the population of all ages are largely those characteristic of middle and old age. Diseases of the heart, cerebral hemorrhage, nephritis, cancer, and diabetes accounted for 65 per cent of the deaths among persons 45 years of age and over, and for 44 per cent of the total deaths 
TABLE 1

Distribution of Population and Deaths by Age in the United States, 1900 and $1935^{1}$

\begin{tabular}{lrrrr}
\hline & \multicolumn{2}{c}{ Population } & \multicolumn{2}{c}{ Deaths } \\
\cline { 2 - 3 } \cline { 5 - 5 } Age in Years & $1900^{2}$ & 1935 & $1900^{2}$ & 1935 \\
\cline { 2 - 4 } & \multicolumn{4}{c}{ Per Cent } \\
All Ages & 100.0 & 100.0 & 100.0 & 100.0 \\
Under 15 & 29.5 & 27.3 & 34.6 & 13.9 \\
Under 5 & 10.4 & 8.1 & 30.3 & 11.3 \\
$5-14$ & 19.1 & 19.3 & 4.3 & 2.6 \\
15-24 & 18.6 & 18.3 & 6.4 & 4.5 \\
25-44 & 31.1 & 29.8 & 16.5 & 13.9 \\
45-64 & 15.7 & 18.7 & 18.2 & 27.6 \\
65 and over & 5.1 & 5.9 & 24.3 & 40.1 \\
\hline
\end{tabular}

${ }^{1}$ Population, United States Registration States of 1900, from Mortality Rates, 1910-1920, Bureau of the Census, 1923, p. 654, and for the United States in 1935, from Special Release of the Bureau of the Census, Feb. 18, 1937. The number of children under 5 years of age in 1935 has been increased to allow for under-enumeration, as estimated by Whelpton in National Resources Committee. Population Statistics, 1. National Data, Washington. D.C., October 1937. Deaths, 1900, from Special Reports, Bureau of the Census, Mortality, 1900-1904, and for 1935, from ibid., Mortality Statistics, 1935.

${ }^{2}$ Population and deaths in the United States Registration States of 1900 (Connecticut. District of Columbia, Maryland, Maine, Massachusetts, Michigan, New Hampshire, New Jersey, New York, Rhode Island, and Vermont).

among persons of all ages occurring in the period 1934-1936. Thompson and Whelpton estimate that by 1980, the number of persons in middle and old age ( 45 years and over) would be 120 per cent larger than in 1930 (and children under 5 years 13 per cent fewer), assuming no increase of the population through immigration, a moderate decline in the birth rate, and a gain of approximately eight years in the expectation of life at birth. ${ }^{2}$ It is apparent that aging of this magnitude would have a marked tendency to increase the death rate from diseases characteristic of middle and old age and, in consequence, the crude death rate from all causes. Population analysts (Thompson and Whelpton ${ }^{3}$; Dublin and Lotka ${ }^{4}$ ) have estimated the amount of increase which may be expected in the crude death rate as a result of aging, on the basis of varying assumptions concerning the future trend in fertility and the amount of decline in age specific mortality rates for all causes of death.

A precise estimate of the effect of aging of the population per se on future death rates from specific causes would involve a similar prediction 
of the future trend of age specific mortality rates from the diseases under consideration, and the application of these hypothetical rates to an estimated population in which survivals were determined by these rates. An undertaking of this nature was not practicable in connection with the preparation of the present report. However, the effect of changing age structure on the death rate from specific diseases may be broadly indicated by assuming that their age specific mortality rates undergo no future decline. A population has been constructed for the United States on the basis of such an assumption in regard to mortality (i.e., a continuation of age specific mortality rates as of 1929-1931) and a moderate decline in fertility. ${ }^{5}$ In 1980 , children under 15 years of age would represent 21.2 per cent of this total estimated population, compared with 29.4 per cent in 1930; and children of these ages would number in 1980, 30.3 million, compared with 36.1 million in 1930. Persons 65 years of age and over would form 11.1 per cent of this estimated population in 1980 and number 15.9 million, compared with 5.4 per cent, and 6.6 million, in 1930 .

The results of the application of the age specific mortality rates for selected causes of death as of 1934-1936 to this estimated population in future years are shown in Figure 1. The age specific death rates used in these computations are not included in this report, since the basic data are readily available in the publications of the Bureau of the Census. ${ }^{6}$

The dotted line in the chart indicates the percentage change in the estimated population between 1935 and decennial periods beginning in 1940. The percentage change in the number of deaths from all causes and from each selected cause of death, estimated on the basis of the respective crude death rates, would be equivalent to that of the total population. Thus, taking into account only the increase in the total population, the number of deaths from each of the selected causes would increase 12 per cent between 1935 and 1980. However, if the age specific mortality rates for these causes of death were applied to the population constituted with respect to age as estimated for 1980, the increase would amount to 92 per cent in deaths from diseases of the heart, 80 per cent in cancer deaths, and 87 per cent in deaths from diabetes. The age variation in mortality from these diseases is similar, the death rates being relatively low prior to middle age and rising sharply thereafter. The tendency of deaths from these causes to increase as the population ages is therefore marked, and of approximately the same order. 


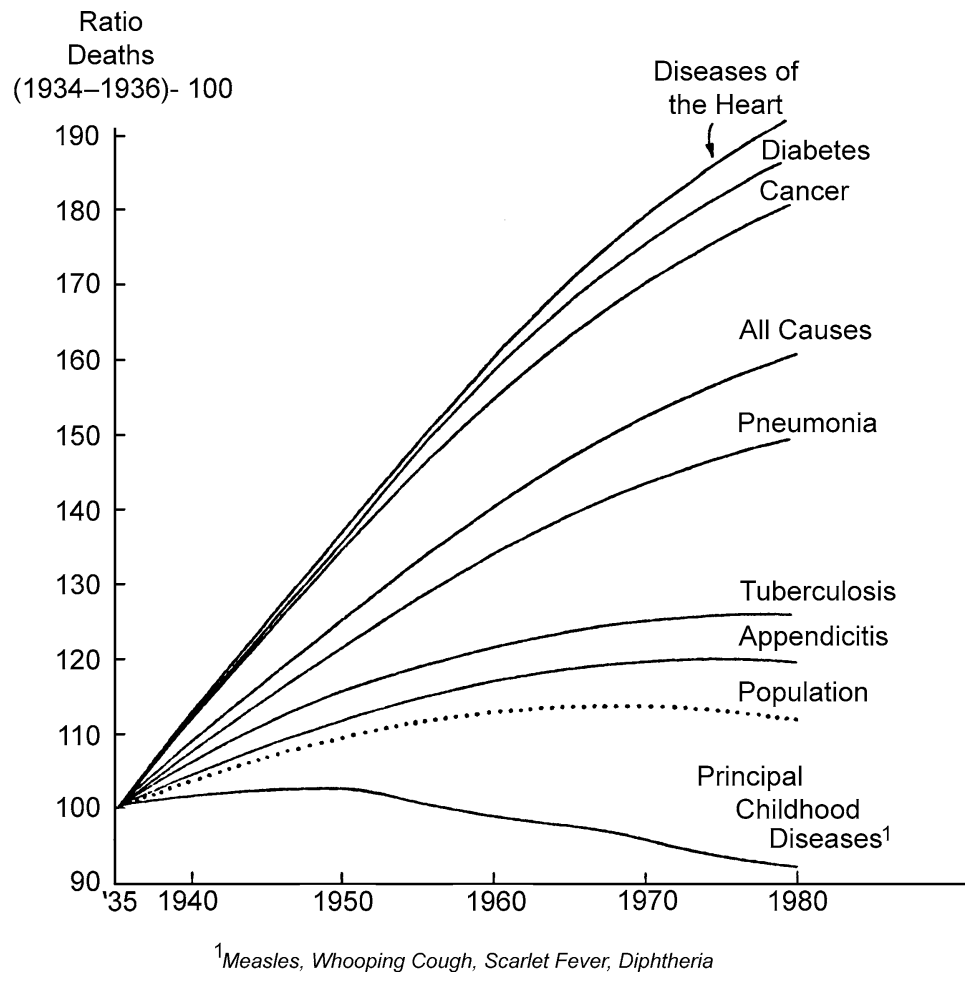

FIG U R E 1. Ratios of Deaths from Selected Causes in the United States, 19401980, Estimated on the Basis of Age-Adjusted Mortality Rates, to Deaths in 1934-1936. Diseases of the coronary arteries and angina pectoris are included with diseases of the heart. Cancer includes other malignant tumors. The designations pneumonia and tuberculosis relate to all forms of these diseases.

Future population changes among children, and, in particular, among children under 5 years of age, are reflected in the trend of deaths from the principal communicable diseases of childhood between 1935 and succeeding periods, estimated on the basis of age specific death rates. In the population as estimated, the number of children under 5 years of age would increase between 1935 and 1950 (the effect of a declining birth rate being offset by a continued increase in the number of women at the principal childbearing ages to the period 1945-1955) and deaths from the common communicable diseases of childhood would show a corresponding rise. A decline in the number of deaths from this group of diseases would accompany the numerical decline in children of these 
ages after 1950. Aging of the population would result in a relatively small increase in deaths from tuberculosis. The death rate from this disease reaches a high level at the early adult ages, and remains high in subsequent age periods. Thus, the decrease in tuberculosis deaths accruing from young adults, who would decline somewhat in the population of the future, would provide a counter-tendency toward the increase in deaths associated with the increment of older persons.

If the mortality rates of the life tables of 1929-1931 (see reference 5) are applied to the population of the United States in 1935 and 1980 distributed by age in accordance with the assumptions adopted, it is found that aging of the population in this period would result in a 61 per cent increase in deaths from all causes. In terms of the crude death rate, this change would represent an increase from a rate of the order of 11 per 1,000 in 1935 to an estimated rate of 17 per 1,000 in 1980 . It is not probable, of course, that so marked an increase in the crude death rate will actually occur, since it seems reasonable to expect some reduction of the age specific mortality rates now prevailing.

\section{The Effect on Frequency and Disability Rates of Illness}

Aging of the population may be expected to result in a relatively lower rate of increase of illnesses than of deaths. After the first year of life, the chance of death is relatively small until the periods of middle and old age are attained. While the incidence of illness shows a similar upward trend at the advanced ages, age variation in the incidence of illness and death presents striking differences prior to this period. In childhood, the mortality rate is high only in the first year, but high frequency rates of illness are observed through the first ten years of life. The incidence of illness falls sharply in late childhood and youth, yet the level of the frequency rate of illness in comparison with the death rate at these ages is relatively high. A further striking difference between the incidence of illness and death is seen in the young adult period, in which the age curve of illness shows a secondary peak, while the death rate, still at a relatively low level, is undergoing a slow increase from the minimal rate observed at ages 10 to 14 years. ${ }^{7,8,9}$ Thus, changes in the structure of the future population prior to the period of middle and old age will have a significant effect on the future incidence of illness. 
However, the aging factor should result in a material increase in the days of disability accruing from illness, since the average duration of illness increases progressively with age in a manner resembling the age incidence of death. The diseases which account for the high frequency of illness in childhood and the young adult period are typically short in duration. Thus, the disability rate is relatively low prior to middle and old age, when a rise occurs which is associated with the increasing incidence of chronic disease. ${ }^{10}$

The records of disabling illness obtained in the National Health Survey, a house-to-house canvass conducted by the United States Public Health Service in 1935-1936, provide a basis for estimating the effect of changing age composition of the population on the future incidence of illness and the volume of disability. The experience of 1,581,577 white persons in thirty-one cities of 100,000 population and over canvassed in this survey has been selected for this purpose.

The illnesses recorded had caused a minimum of seven consecutive days of disability, i.e., time lost from school, gainful or other work, or other usual activities, in the twelve months preceding the date of the canvass. The method and scope of the survey and its broad results have been reported in earlier publications. ${ }^{11,12}$ In the interpretation of subsequent estimates based on data of the National Health Survey, it should be noted that the survey records relating to tuberculosis, mental disease and defect, cancer, and syphilis are incomplete because of certain limitations inherent in the house-tohouse method of enumerating illness. The informant may fail to include on the family roster persons confined in tuberculosis sanatoria, or in institutions for the mentally diseased or defective; or, because of long confinement (as of the mentally diseased or defective), such persons may have no family status. Inadequate or incorrect information concerning the diagnosis of cases of cancer and syphilis, or unwillingness to report such cases to the enumerator, probably accounts for the incompleteness of records of these diseases obtained from laymen. Under-enumeration of illness due to certain of these causes has been observed also in the results of the representative family survey made by the Committee on the Costs of Medical Care. ${ }^{13}$

The nature of age variation in the frequency and disability rates of illness classified by cause observed in this population is shown in Table A1. The age specific rates shown here, except those relating to confinements terminating in live births, have been applied to the estimated population of the United States in 1935, and to the 1980 pop- 
ulation estimated by the method outlined previously. The number of confinements terminating in live births has been estimated for 1935 on the basis of the live births actually registered in the United States in that year (increased to allow for under-registration), the resultant days of disability being estimated from the average duration as observed in the large cities canvassed in the National Health Survey. For 1980, the number of disabilities associated with confinement, and the days of disability associated therewith, were reduced in accordance with the decline in the birth rate assumed in the construction of the 1980 population. The age specific frequency and disability rates of illness due to all causes except confinement cases were assumed to prevail at the same rate in 1980 as in 1935 .

The results of these estimates of the future incidence of disabling illness and the resulting days of disability for illness of specific causes are shown graphically in Figure 2. If the number of disabling illnesses due to these specific causes increased at the rate of growth of the total population, a 12 per cent increase would represent the change between 1935 and 1980. However, the total increase in this period would amount to 56 per cent in cancer cases, 51 per cent in illnesses due to the degenerative diseases, and 41 per cent in illnesses due to rheumatism, on the basis of estimates which take into account the age specific frequency rates of illness due to these causes. In nervous and mental disease, the total increase would amount to 23 per cent. The effect of aging on the incidence of the group of nervous and mental diseases would be increased by a more complete representation of cases of insanity, but it is estimated that only 9 per cent of the illnesses included in the broad group of nervous and mental diseases as used here were due to this cause. ${ }^{14}$ Under-enumeration of the insane, usually residents of institutions, is a defect of the technic of the family survey.

On the other hand, the changed age structure of the population would result in no material increase in illnesses due to diseases of the respiratory system (exclusive of pneumonia, tonsillitis, and respiratory tuberculosis). Illnesses due to the communicable diseases (in the classification used here, largely those of childhood), tonsillitis, and disabilities associated with the puerperal state would be fewer in number in 1980 than in 1935, due to the decrease in births and in the child population. Thus, several of the most frequent causes of illness would not be affected by the factor of aging per se. Furthermore, the large proportionate increase of illness due to the characteristic chronic diseases of middle and old age 
associated with aging of the population represents an actual increase of small magnitude in certain chronic diseases of low incidence.

The average age specific frequency rates of illness of all causes take these various factors into account. When these rates are applied to the

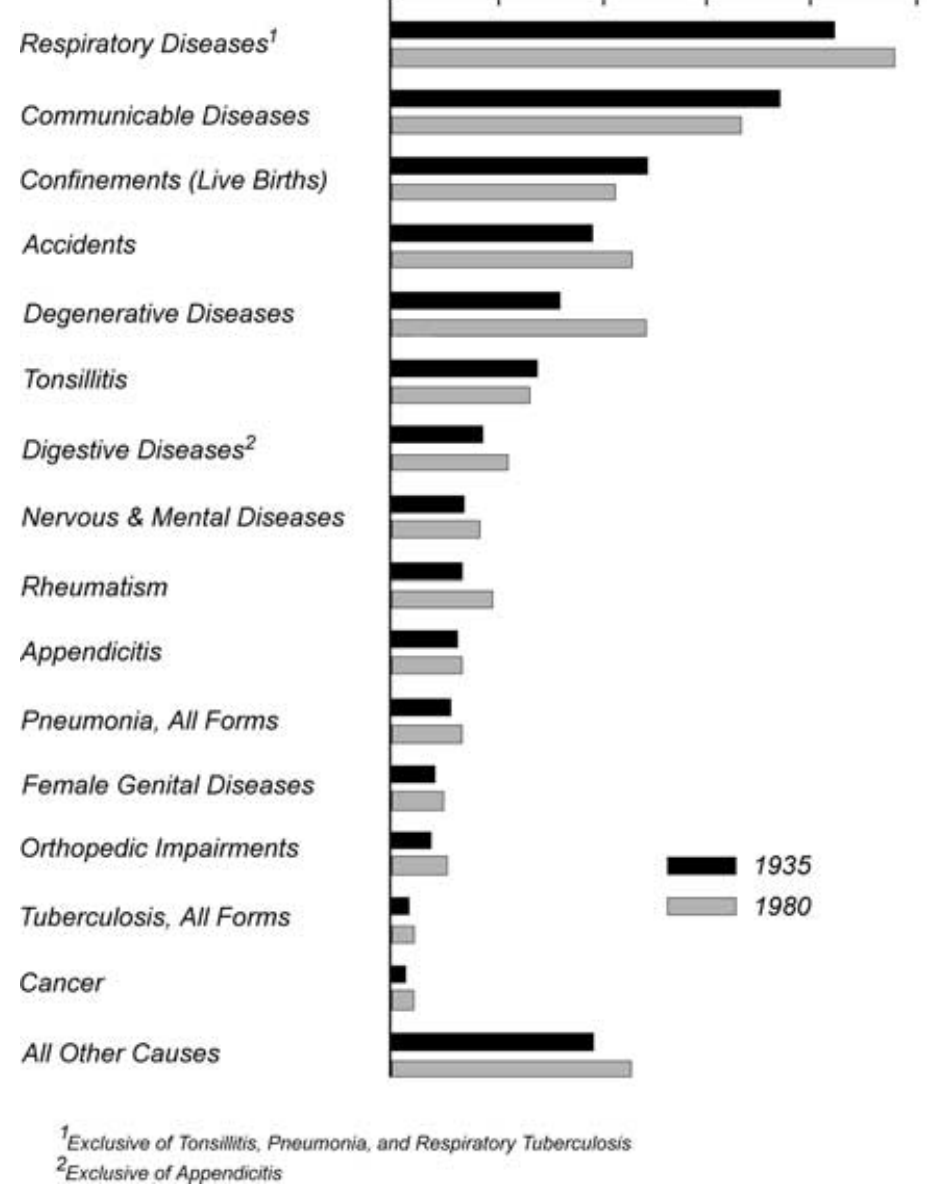

FIGURE 2. Number of Disabling Illnesses and Days of Disability in a TwelveMonth Period in the United States in 1935 and 1980 according to Cause, Estimated on the Basis of the Frequency and Disability Rates Observed in Cities of 100,000 and over Canvassed in the National Health Survey, 1935-1936, Adjusted for Age. (The method of estimating the data relating to confinements terminating in live births is described on page 581 of the text.) 


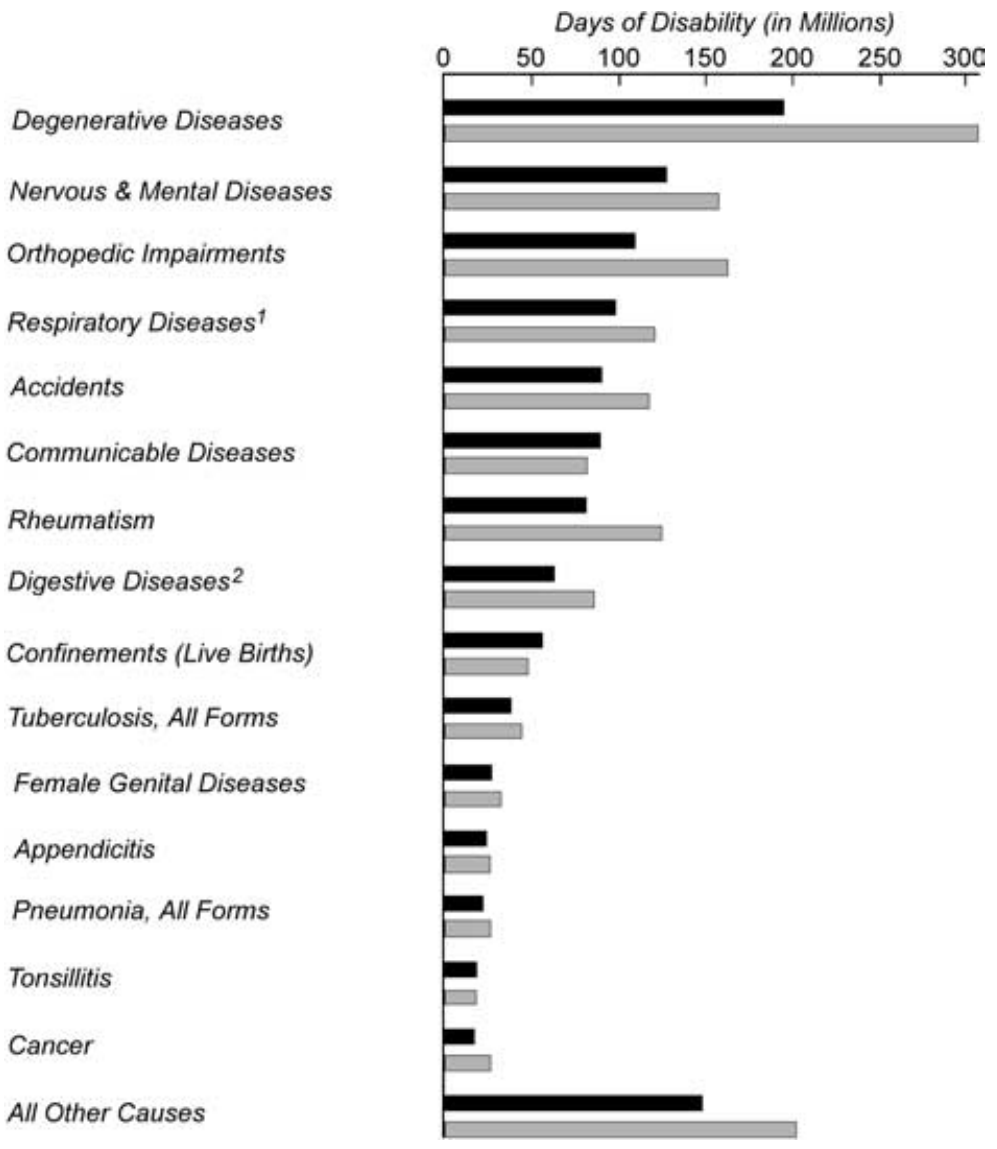

FIGURE 2. (Continued)

estimated population in 1980, it is found that the total number of disabling illnesses would show no excess above the number expected on the basis of population growth. However, the total days of disability accruing from illnesses of this category would increase 31 per cent as a result of changing age composition, compared with a 12 per cent increase in the total population. The notable difference between the effect of aging of the population on illnesses and the resultant days of disability arises from the difference in rank of the characteristic chronic diseases of the advanced ages with respect to their frequency and severity, as measured by duration. These diseases account for a large volume of disability. Thus, aging would produce both a high relative and absolute increase 
in the days of disability accruing from these causes. Furthermore, the increased volume of chronic disability would not be reduced to any measurable degree by the decrease in the volume of disability at the younger ages, since the diseases characteristic of this period, while frequent in occurrence, are short in duration.

\section{The Effect on Services for Care of the Sick}

The effect of an aging population on the services required in the prevention of disease and the treatment of the sick is a subject of major interest in connection with future population trends. Will an aging population produce significant changes in the amount of service given by the private physician in home and office practice, and in the volume of hospital patient days? What will be the effect of an aging population on bedside nursing care of the sick? How will an aging population alter the existing program of preventive services provided by health departments and official and nonofficial nursing agencies?

A basis for speculation concerning trends relating to services for care of the sick is again provided by the results of the canvass of white persons in thirty-one large cities included in the National Health Survey. The experience of this population with respect to medical and nursing care of disabling illness in a twelve-month period is summarized in Tables A2A5, in which disabling illnesses of the various categories have been classified by age according to diagnosis. ${ }^{15}$

Special note should be made of the nature of the data relating to hospitalized illness shown in Table A3. As noted previously, disabling illnesses due to tuberculosis and nervous and mental disease were incompletely enumerated in the National Health Survey. As a result, the survey records relating to medical and nursing care of these two groups of patients understate the true incidence of these patients in the various categories, as well as the frequency of services received. This deficiency is particularly marked with respect to the volume of hospital patient days for the tuberculous and mentally diseased as observed in the survey. For this reason, the experience of all patients hospitalized for the treatment of tuberculosis or nervous and mental disease has been excluded in subsequent computations. Thus, the "total number of hospital patients" and the "total number of hospital patient days" as employed in the following discussion do not represent the incidence of hospital patients and the frequency of hospital days for illness of all causes, as shown in Table A3, but represent the experience of all 
patients exclusive of the tuberculous and the mentally diseased. This exclusion results in a residual group of patients which approximates those treated in general hospitals. The approximate composition of this group should be emphasized, since it is evident that patients with tuberculosis or nervous and mental disease who may have been treated in general hospitals are excluded by the procedure adopted. The records of the National Health Survey do not make possible an exact segregation of general hospital patients.

The general effect of an aging population on medical and nursing services and hospital facilities may be predicted by comparing the distribution of patients of the several categories, and the corresponding services, according to the causes of illness for which the services were received, as shown in these tables. Patients attended for illness due to the communicable diseases, tonsillitis and appendicitis, and confinement cases occurred with high frequency in the periods of childhood, youth, or early adult life, and were relatively infrequent among older adult patients. Cancer, the degenerative diseases, diseases of the digestive system (exclusive of appendicitis - in the classification used here, chiefly chronic in nature), rheumatism, and orthopedic impairments were among the major causes of illness of patients in middle and old age, and were relatively infrequent diagnoses among younger patients. In this experience, patients attended for the types of illness which were characteristically high in frequency at the younger ages outnumbered patients treated for the chronic diseases of middle and old age in each medical and nursing category.

In respect to the volume of medical and nursing services absorbed, the relative position of these two groups of patients was reversed. The communicable diseases accounted for 14.2 per cent of all patients treated by physicians outside the hospital, but utilized only 7.8 per cent of all physicians' services. Tonsillitis (including operations on the tonsils or adenoids) accounted for 11.8 per cent of all hospital patients (exclusive of the tuberculous and all mental and nervous cases) but for only 1.6 of all hospital days of care. Hospitalized confinements terminating in live births represented 20.8 per cent of all hospital patients, but only 12.4 per cent of all hospital patient days were absorbed by this group. On the other hand, patients treated for diseases of the degenerative group represented only 9.5 per cent of all home, office, or clinic patients, but utilized 16.4 per cent of all services of this category. These diseases accounted for 7.6 per cent of all hospital patients and for 13.4 per cent of 
the patients attended by private duty nurses, but corresponding services for these patients represented, respectively, 13.1 and 23.0 per cent of the total. Similarly, patients treated for cancer, rheumatism, orthopedic impairments, or chronic diseases of the digestive system accounted for a disproportionately large amount of medical and nursing services. It may be expected, therefore, that aging of the population would tend to increase the number of services provided by physicians, general hospitals, and private duty nurses to a relatively greater degree than the number of patients. Thus, more physicians, private duty nurses, and general hospital beds might be required for a given case load, as an indirect result of its changed age composition and the increased need for services for patients with the chronic diseases characteristic of middle and old age.

Estimates of the effect of the age composition of the population as estimated for 1980 on medical and nursing services for important causes of disabling illness are shown graphically in Figure 3. The age specific frequency rates of services for patients of the various categories classified by diagnosis, as shown in Tables A2-A5, have been applied to the estimated population of the United States in 1935, and to the 1980 population constructed on the basis of assumptions previously noted.

An exception to this procedure was made in estimating the number of confinements terminating in live births in the various categories, and services for these cases. The number of confinements terminating in live births attended by a physician in the hospital in 1935 was obtained from data published by the Bureau of the Census, ${ }^{16}$ the number of hospital days of care for these patients being computed on the basis of the average hospital duration as observed in large cities canvassed in the National Health Survey (Table A3). However, no published data were available concerning the total number of confinements attended by a physician (including care of patients delivered in the home, and home or office care of hospitalized patients, in the period prior to or following hospitalization), and the number of confinements receiving bedside care from a private duty or visiting nurse. Estimates relating to confinements of these categories therefore were derived from the experience of live births in the large cities canvassed in the National Health Survey (Tables A2, A4, A5), the actual number of live births occurring in the United States in 1935, increased to allow for underregistration, forming the basis for these estimates. It was assumed that the relative number of confinements receiving hospital, home, or office medical care, or bedside care from a private duty or visiting nurse, would undergo no change in 1980, but the absolute number of cases in the various categories and the corresponding services were reduced 


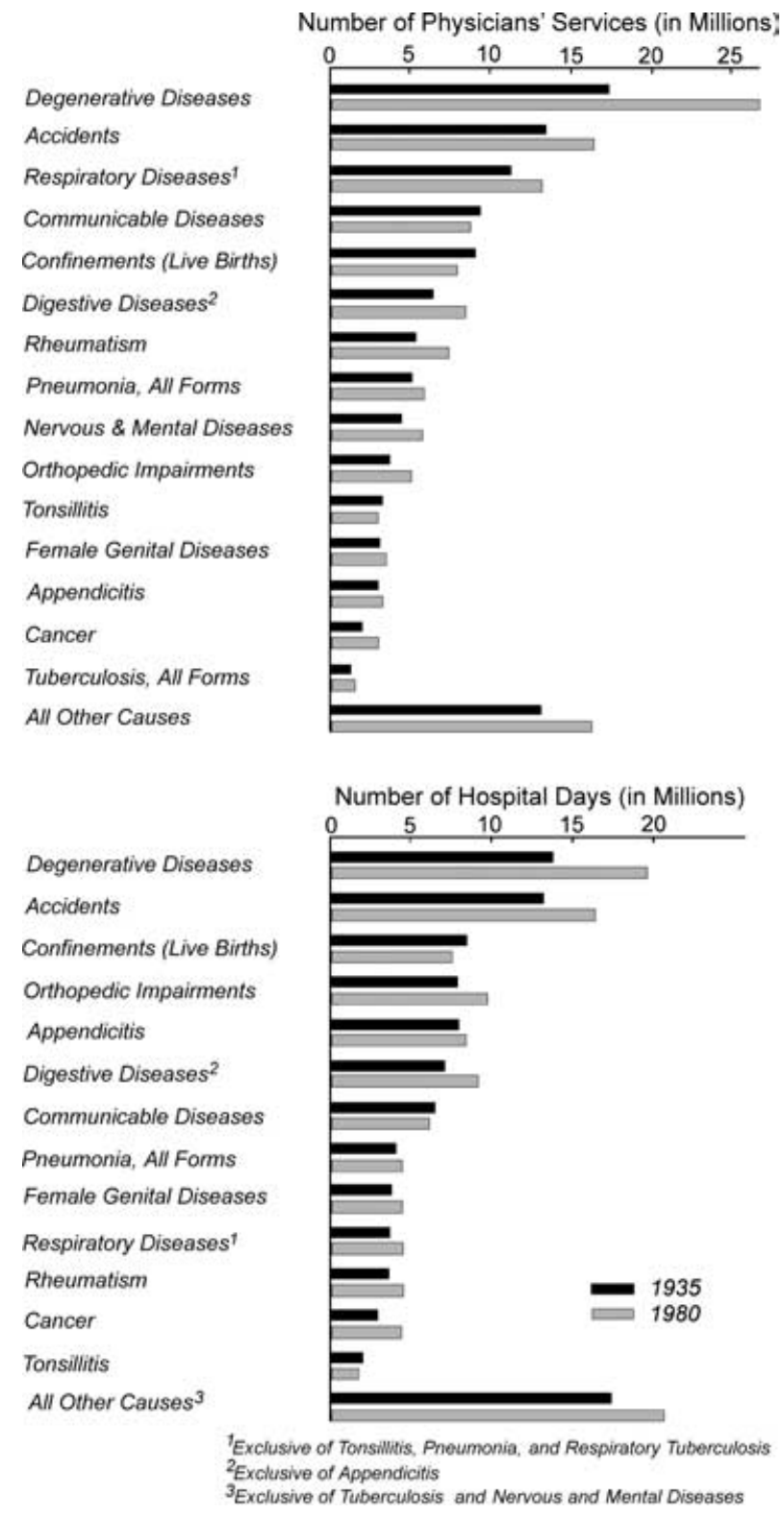

FIGURE 3. Number of Disabling Illnesses Receiving Medical and Nursing Care in a Twelve-Month Period and Number of Services in the United States in 1935 and 1980, according to Cause, Estimated on the Basis of the Experience of the National Health Survey, 1935-1936, Adjusted for Age. (The method of estimating the data relating to confinements terminating in live births is described on pages 586 and 587 of the text.) 


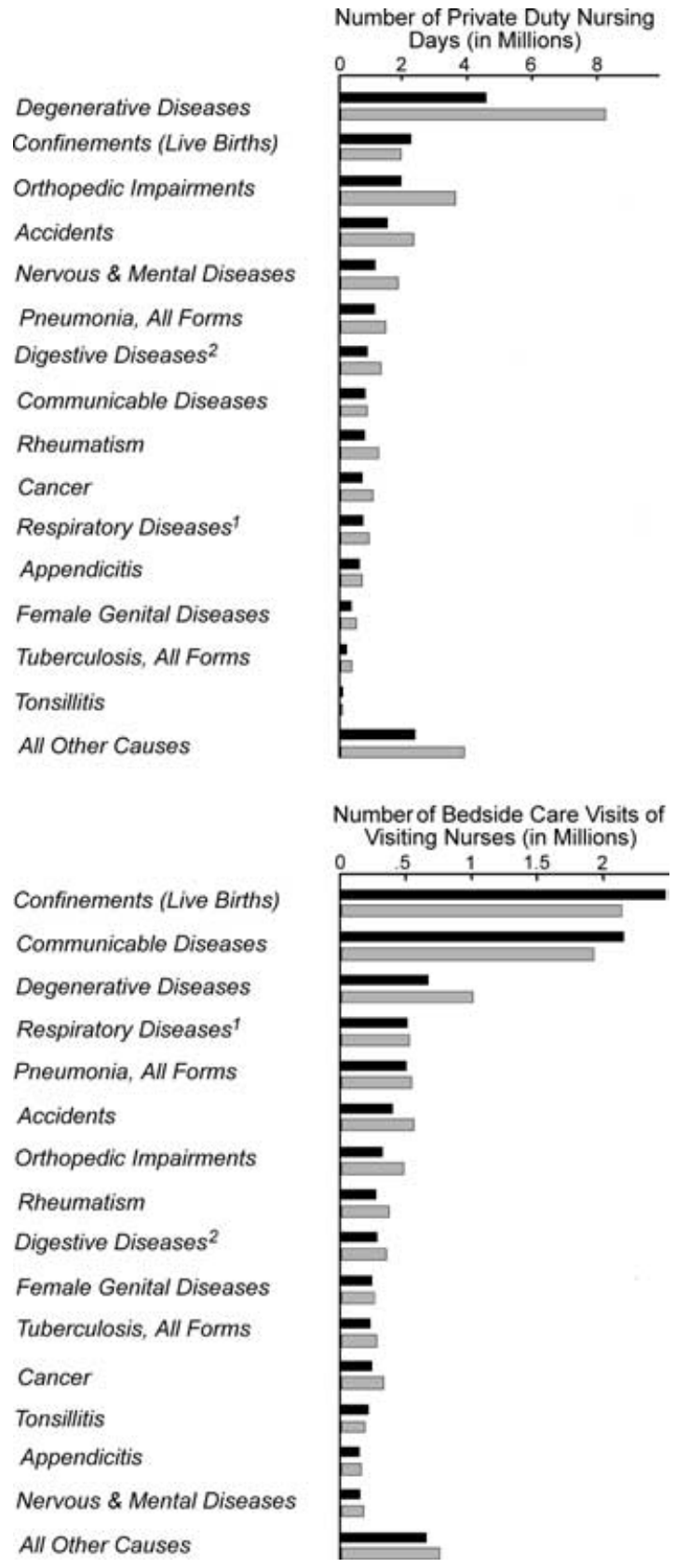

FIGURE 3. (Continued) 
in accordance with the decline in the birth rate assumed in the construction of the 1980 population

The direction of the change between 1935 and 1980, i.e., an increase or decrease in services for patients with a given diagnosis, follows the pattern which has been observed in earlier estimates of the effect of a changed age structure on the future incidence of illness and death. Medical and nursing services for illness due to the degenerative diseases would be increased to a marked degree as a result of the aging factor alone, and services for patients with cancer, rheumatism, or the chronic diseases of the digestive system would show a generally similar trend. Taking the age specific frequency rates of services into account, by 1980 , the chronic patients included in these four diagnostic groups would require services amounting to approximately 10.7 million consultations with a physician, 6.8 million hospital patient days, and 4 million days of care by a private duty nurse, in addition to the services which would be required if estimated solely on the basis of population growth. On the other hand, the increase in medical and nursing services for older patients with chronic disease would be offset, to a degree varying with the type of service, by the decrease in younger patients. Thus, in 1980, patients with acute communicable disease, tonsillitis, appendicitis, and confinement cases would require a total of approximately 27.1 million consultations with a physician, estimated solely on the basis of the increase in total population, but the number would be 4.4 million less if the age composition of the population were taken into account. Similarly, hospital days of care for patients with these diseases would be reduced in 1980 by 3.9 million days.

While the effect of population changes on institutional facilities required for care of the tuberculous and mentally diseased is incompletely measured by the experience of the National Health Survey in absolute terms, the relative nature of trends in these facilities is more adequately represented by the survey data. Between 1935 and 1980, hospital patient days for the tuberculous would increase 10 per cent as a result of the changed age structure of the population (i.e., on the basis of estimates made by application of the age specific rates included in Table A3), while the increase would amount to 12 per cent on the basis of total population growth. Thus, the assumed changes in age composition would tend to reduce somewhat the special hospital facilities required for care of the tuberculous. Hospital patient days for the group of patients with 
nervous and mental disease would show an increase of 21 per cent in this period as a result of aging of the population. However, the actual increase would be well in excess of this figure, since, in the Health Survey experience, the number of hospital patient days for the insane forms a relatively lower proportion of the total patient days of the nervous and mental group than in the general population. Dorn estimated the effect of aging of the population on the facilities of mental hospitals by applying the age-specific first commitment rates in these special hospitals in New York State (1929-1931) to the population of the United States in 1960 as estimated by Thompson and Whelpton. His results indicated that in 1960 the number of first admissions would be nearly twice as large as in $1930 . .^{17}$

The influence of a changed age structure of the population on the total case load of physicians, nurses, and hospitals measures the composite effect of the increase in patients of middle and old age, and the associated decrease in patients drawn from the younger age groups. Estimates of this nature are shown graphically in Figure 4. They are based on age specific frequency rates of patients of the several medical and nursing categories, and of the corresponding services, derived from the results of both the National Health Survey (Table A6) and the survey made by the Committee on the Costs of Medical Care in 1928-1931 (Table A7). A comparison of this kind seemed of interest as an indication of the effect of population changes on the medical services for all types of illness (i.e., both disabling and nondisabling), recorded in the survey of the Committee on the Costs of Medical Care, as distinguished from the records of the National Health Survey, which relate only to services for illness disabling for a minimum of seven consecutive days in a twelve-month period. Estimates based on the Committee's data have additional value since the surveyed families were drawn from large and small cities and rural areas, while the results of the National Health Survey selected for these estimates relate only to surveyed families in cities of 100,000 population and over. The rates employed in estimates based on the results of the Committee's survey were obtained from an analysis of the Committee's data made by Collins, adjusted for the purposes of the present report. ${ }^{18}$ In the estimates of the trend in hospital patients and hospital patient days the experience of all hospitalized illnesses in which tuberculosis or nervous or mental disease was the sole or primary cause of the illness has been excluded from the data of both surveys. 


\section{Survey, Committee on the Costs of Medical Care}

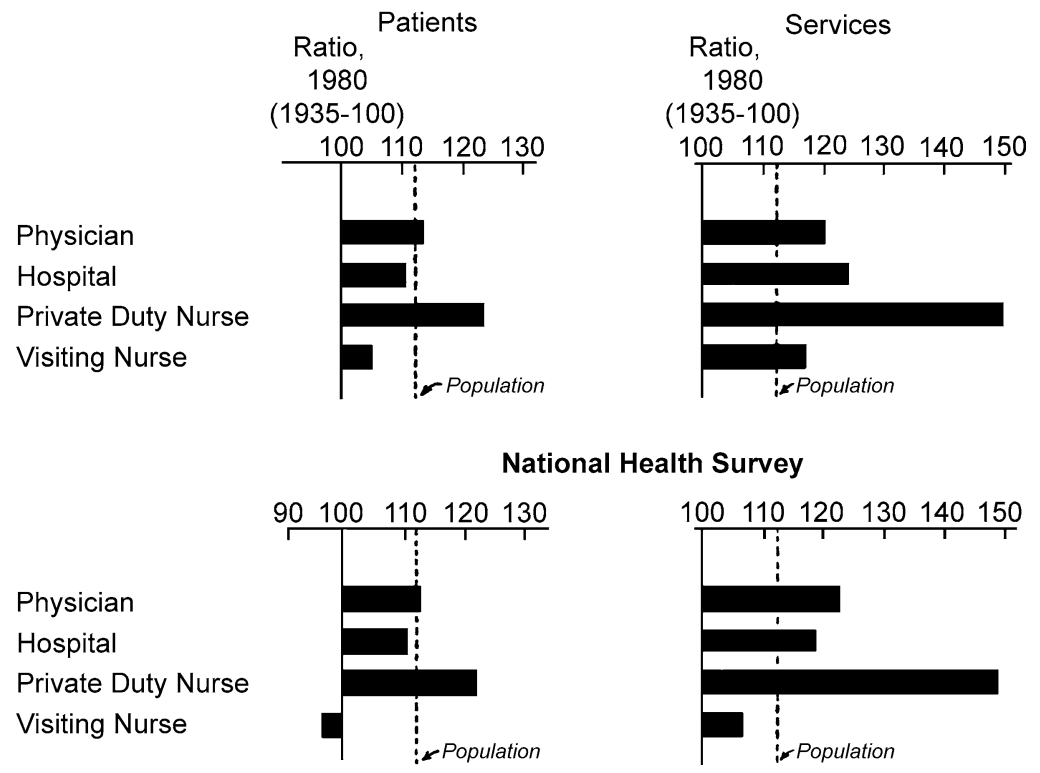

FIGURE 4. Ratios of Patients Receiving Medical and Nursing Care in a Twelve-Month Period, and of the Corresponding Services, in the United States in 1980, to Patients and Services in 1935, Estimated on the Basis of the Experience of the Survey of the Committee on the Costs of Medical Care, 1928-1931, and the National Health Survey, 1935-1936, Adjusted for Age. Hospital patients (and services) are exclusive of the experience of hospitalized cases of tuberculosis and nervous and mental disease. The definitions of the several categories of patients are included in Tables A6 and A7.

It has been assumed that the age specific frequency rates of patients receiving the various types of medical and nursing care, and of services received, as observed in these surveys, would prevail in 1980 for all patients except confinement cases, for which the following procedure was adopted. The total number of confinements terminating in live births in the United States in 1935 was estimated by increasing the actual number of live births reported in this year to allow for under-registration. For all categories except hospitalized patients, the distribution of confinements according to type of attendant at delivery, and the number of physicians' and nurses' services received in 1935, were estimated on the basis of (1) the experience of large cities included in the National Health Survey and (2) the survey of the Committee on the Costs of Medical Care. The number of confinements terminating in live births attended by a physician in the hospital was obtained from data published by the Bureau of the 
Census (United States Department of Commerce 1937), the number of hospital days of care for these patients being computed on the basis of the average hospital duration as observed in the survey of the Committee on the Costs of Medical Care. Thus, in the estimates based on the results of these surveys, the number of hospitalized confinements and hospital days of care for these patients is uniform, but the number of confinements of other categories and the corresponding services varies according to the experience of the survey under consideration. It was assumed that the number of confinements in the various categories, and the services received, would form the same proportion of the respective totals in 1980 as in 1935 , but the absolute number of the attended confinements and services for these patients in 1980 was reduced in accordance with the decline in the birth rate assumed in the construction of the 1980 population. The estimates made by the methods outlined were used as the basis for frequency rates of confinement cases and services, therefore, in the estimated population of the United States in 1935 and 1980. These rates, taken as the equivalent of age-adjusted rates, when combined with the age-adjusted rates for patients and services of the several categories, exclusive of confinements, formed age-adjusted rates for all patients of each category.

As the results plotted in Figure 4 indicate, no material increase in the total case load of physicians in home or office practice, or of general hospitals would occur as the result of the assumed changes in age composition of the population between 1935 and 1980. The increment of patients in middle and old age would be balanced by the decline in younger patients. Hospital patients, exclusive of the tuberculous and mentally diseased, if estimated on the basis of age specific incidence rates, would be somewhat less numerous in 1980 than would be predicted with reference to the rate of population growth. However, as a result of aging of the population, the increase in the number of physicians' services would amount to 8 to 11 per cent more than the percentage increase in the population ( 8 per cent, data of the Committee on the Costs of Medical Care; 11 per cent, data of the National Health Survey) between 1935 and 1980. In this period, the factor of aging alone would account for an increase in hospital days of care (exclusive of patient days for the tuberculous and mentally diseased) amounting to 7 per cent, as estimated on the basis of results of the National Health Survey, and 12 per cent, on the basis of the experience of the Committee on the Costs of Medical Care. Thus, the increase in the volume of physicians' services and hospital days of care resulting from the increment of older patients indirectly would alter the case load of physicians and hospitals, and additional medical personnel 
and hospital facilities might be required to maintain medical care at its present standards.

Among the various services for care of the sick, aging of the population would effect the greatest change in the field of private duty nursing. The factor of aging alone would produce a marked increase in both the number of patients of private duty nurses and the number of nursing days of care. On the other hand, patients receiving the services of visiting nurses would increase at a rate lower than the total population under the assumed changes in age composition. On the basis of the results of the National Health Survey, the volume of visiting nurse service would also increase at a rate lower than the rate of population growth if changes in age structure were taken into account. However, estimates based on the records of the Committee on the Costs of Medical Care show an opposite trend, the volume of the services of visiting nurses increasing as a result of changes in age composition between 1935 and 1980 at a relatively higher rate than that of the total population.

\section{The Effect on Organized Health Services}

The activities which form an established part of the program of health departments and nonofficial health agencies are directed in relatively small degree to health supervision of persons of middle and old age. This limitation is a natural consequence of the traditional restriction of public health services to those involved in the control of preventable disease. Thus, the changing age structure of the population may be expected to produce effects opposite in nature on public health and medical services. The increment of older persons would tend to increase the total volume of home and office medical services as well as the days of hospital care. On the other hand, a decline in the number of children, youth, and young adults would result in a reduction of the volume of preventive services which now receive the major emphasis of organized health agencies. Activities for the control of tuberculosis would share in this decline. The program for the control of venereal disease would be less affected since the decline in services for young adults would be balanced to some extent by an increase in services for those in middle age. Aging of the population will give impetus to the further development of activities in the control of pneumonia and cancer. Health supervision of the worker, and in particular the worker of middle age, will receive 
increasing recognition as a strategic method of averting certain health problems of the aged.

\section{General Implications}

Solution of the health problems associated with aging of the population will require the intensive application of existing methods for the prevention of disease to a larger number of the population than is now receiving the benefits of preventive medicine. Health gains in infancy and childhood have been chiefly responsible for the increase in average life expectancy, yet this field offers opportunity for further substantial improvement. Deaths of infants from congenital malformations and debility, birth injuries, and the broad group of the diseases of early infancy average about 63,000 annually, these conditions taken together ranking among the leading causes of death in the total population of all ages. Adequate prenatal and infant care is of demonstrated value in reducing both puerperal and neonatal mortality. School children and workers in industry afford opportunity for effective group health supervision. The specific attack on tuberculosis and the venereal diseases provides an additional approach to the health problems of young adults.

Yet at certain points, the provision of preventive health services alone leaves the greater part of the health problem unsolved. The maternity case requires competent attendance at delivery as well as supervision in the prenatal period. Control of the communicable diseases of childhood requires not only preventive measures, but treatment of the sick child. Tuberculosis and syphilis control involves both case-finding and adequate treatment of cases and their contacts when found. The characteristic chronic diseases of middle and old age are subject to control primarily through therapeutic measures. On the whole, organized health agencies assume relatively little responsibility for making these curative services available. Individual, rather than community, income is the chief determining factor in the receipt of medical care, and individual income is generally recognized to be inadequate for medical needs in a large proportion of the population, particularly among the aged.

A possible solution of this impasse lies in the employment of public funds to provide both preventive and curative services for those groups of the population unable to support the costs of such care from individual income. The promotion of such a plan through the system of Federal 
grants-in-aid would be achieved by a national health program such as has been proposed by the President's Interdepartmental Committee to Coordinate Health and Welfare Activities. The need for a comprehensive health program of wide scope is daily brought to the attention of the administrators of the various titles of the Social Security Act. Under the public assistance titles, there is no adequate means of providing Federal grants for medical care. The appropriations made available under Title VI (Public Health Work) have been insufficient to support more than the first steps in the development of public health services adapted to the needs of those in middle and old age. Disability insurance is a pressing need which will increase in importance as the population ages. Small grants are made under the Act for vocational rehabilitation but they by no means meet the needs in this field.

Finally, an important approach to the solution of this broad problem is offered through the extension of research in the cause and control of the chronic diseases characteristic of advanced life. Effective control of certain of these diseases, of which cancer is an outstanding example, is in part dependent on the demonstration of the etiologic agents involved. Opportunity should be provided for the appraisal of existing methods of diagnosis and treatment, and the exploration of new procedures designed to bring the chronic diseases under early control. But an equally fruitful field of research consists in the development of public health methods which will solve the unique problems involved in coordinating the control of the chronic diseases in the community health program.

\section{References}

1. Dublin, Louis I.: Chapter VII. The Problem of Old Age, an address presented at the 17 th Annual New York City Conference of Charities and Corrections, May 13, 1926. Published in Health and Wealth: A Survey of the Economics of World Health. New York, Harper \& Brothers, 1928.

2. Thompson, Warren S. and Whelpton, P.K.: Report included in The Problems of a Changing Population. Washington, D.C., National Resources Committee, 1938.

3. Thompson, Warren S. and Whelpton, P.K.: Population Trends in the United States. New York and London, McGraw-Hill Book Company, Inc., 1933.

4. Dublin, Louis I. and Lotka, Alfred J.: Length of Life. New York, The Ronald Press Company, 1936. 
5. The population was constructed by Karpinos according to the following method: The population of the United States enumerated in the Census of 1930, distributed by five-year age groups according to sex and race, was taken as a base. "Other colored" persons, exclusive of Negroes, were included in the white population. Persons of unknown age were distributed proportionately in each sex-race group. The number of children under 5 years of age was corrected for under-enumeration on the basis of an estimate by Thompson and Whelpton, included in Table 1 of Population Statistics. 1. National Data. National Resources Committee, Washington, D.C., 1937.

For the white population, an average net reproduction rate of .980 for the period 1931-1935 was reported in Population Index, April 1939,5 , No. 2, based on data supplied by the Statistical Bureau of the Metropolitan Life Insurance Company. From this rate taken as a base, a gradual decline in fertility was assumed in succeeding years, reaching a net reproduction rate of .870 in 1980 . The assumed rate of decline in fertility corresponds closely with the "medium" fertility assumption for the white population made by Thompson and Whelpton, as stated in Population Statistics. 1. National Data, referred to in the first paragraph above. For the Negro population, it was assumed that a net reproduction rate of 1.00 would prevail without change in the period 1930-1980. On the basis of these assumptions, the number of births in the total population would decline 12.4 per cent between 1935 and 1980 .

Survivals based on the life tables for the United States, exclusive of Texas and South Dakota, 1929-1931, prepared by the Metropoli$\tan$ Life Insurance Company, were used in the construction of the population, the life tables for Continental United States prepared by the Bureau of the Census having been published subsequent to the period when the basic computations for these population estimates were made.

The age distribution of this estimated total population in 1980 would be as follows:

\begin{tabular}{lccccc}
\hline $\begin{array}{l}\text { Age } \\
\text { in Years }\end{array}$ & $\begin{array}{c}\text { Number } \\
\text { (in Thousands) }\end{array}$ & Per Cent & $\begin{array}{c}\text { Age } \\
\text { in Years }\end{array}$ & $\begin{array}{c}\text { Number } \\
\text { (in Thousands) }\end{array}$ & Per Cent \\
\hline Total & 142,898 & 100.0 & $25-34$ & 21,004 & 14.7 \\
Under 5 & 10,034 & 7.0 & $35-44$ & 19,940 & 14.0 \\
$5-9$ & 10,103 & 7.1 & $45-54$ & 18,254 & 12.8 \\
$10-14$ & 10,202 & 7.1 & $55-64$ & 16,769 & 11.7 \\
$15-19$ & 10,288 & 7.2 & 65 and & & 11.1 \\
$20-24$ & 10,377 & 7.3 & over & 15,927 & \\
\hline
\end{tabular}

6. The annual reports on mortality statistics published by the United States Bureau of the Census (years 1934-1936) were used as the 
source of the data on deaths. An unpublished estimate of the population of the United States in 1935 by Bernard D. Karpinos was used in computation of the death rates.

7. Falk, I.S.; Klem, Margaret C.; and Sinai, Nathan: The Incidence of Illness and the Receipt and Costs of Medical Care among Representative Families. Chicago, Illinois, The University of Chicago Press, 1933.

8. Collins, Selwyn D.: A General View of the Causes of Illness and Death at Specific Ages. U.S. Government Printing Office, Washington, Public Health Reports, February 22, 1935, 50, No. 8.

9. Holland, Dorothy F.: Disabling Diseases of Childhood. American Journal of Diseases of Children, December 1939, Vol. 58.

10. Collins, Selwyn D.: Cases and Days of Illness among Males and Females with Special Reference to Confinement to Bed. U.S. Government Printing Office, Washington, Public Health Reports, January 12, 1940, 55, No. 2. See also the publication noted in reference 9.

11. Perott, George St.J.; Tibbitts, Clark; and Britten, Rollo H.: The National Health Survey: Scope and Method of the Nation-Wide Family Canvass of Sickness in Relation to Its Social and Economic Setting, U.S. Government Printing Office, Washington, Public Health Reports, September 15, 1939, 54, No. 37. See also the publication noted in reference 9 .

12. Britten, Rollo H.; Collins, Selwyn D.; and Fitzgerald, James S.: Some General Findings as to Disease, Accidents, and Impairments in Urban Areas. U.S. Government Printing Office, Washington, Public Health Reports, March 15, 1940, 55, No. 11.

13. The incomplete enumeration of institutional cases in the survey of the Committee on the Costs of Medical Care is indicated by the fact that the number of hospital days per capita recorded for patients in tuberculosis and mental hospitals in 1928-31 was .19. (See reference 7.) On the basis of data in The Census of Hospitals of the American Medical Association relating to the year 1930, hospital days for patients in these institutions in the country as a whole amounted to 1.40 per capita.

14. Based on the experience of 280,073 white persons in eight large cities canvassed in the National Health Survey. Comparable data for all cities of 100,000 population and over canvassed in this survey are not available.

15. Additional data relating to the receipt of medical care as observed in the National Health Survey are included in Perrott, George St.J. and Holland, Dorothy F.: Health as an Element in Social Security. The Annals of the American Academy of Political and Social Science, Philadelphia, March 1939, 202, and Britten, Rollo H.: Receipt of Medical Services in Different Urban Population Groups. Public Health Reports. See also the publication noted in reference 9. 
16. United States Department of Commerce, Bureau of the Census, Vital Statistics, Special Reports, June 19, 1937, 3, No. 27, p. 135.

17. Dorn, Harold F.: The Incidence and Future Expectancy of Mental Disease. U.S. Government Printing Office, Washington, Public Health Reports, November 11, 1938, 53, No. 45.

18. The frequency rates of illness attended by a medical practitioner according to age, based on the results of the survey of the Committee on the Costs of Medical Care, were estimated from rates included in a report of the results of the Committee's survey as analyzed by Collins (Collins, Selwyn, D.: Frequency and Volume of Doctors' Calls among Males and Females in 9,000 Families, Based on NationWide Periodic Canvasses, 1928-31. Public Health Reports, November 1, 1940, 55, No. 44.).

The rates used in estimates relating to the receipt of hospital and nursing care are based on unpublished data from the survey of the Committee on the Costs of Medical Care made available from current studies of Dr. Selwyn D. Collins. See also reference 7 for a general summary of the results of the survey of the Committee on the Costs of Medical Care.

Acknowledgement: The authors make grateful acknowledgment of the contribution of Bernard D. Karpinos, Assistant Statistician, United States Public Health Service, represented in the population forecasts utilized in this paper. 


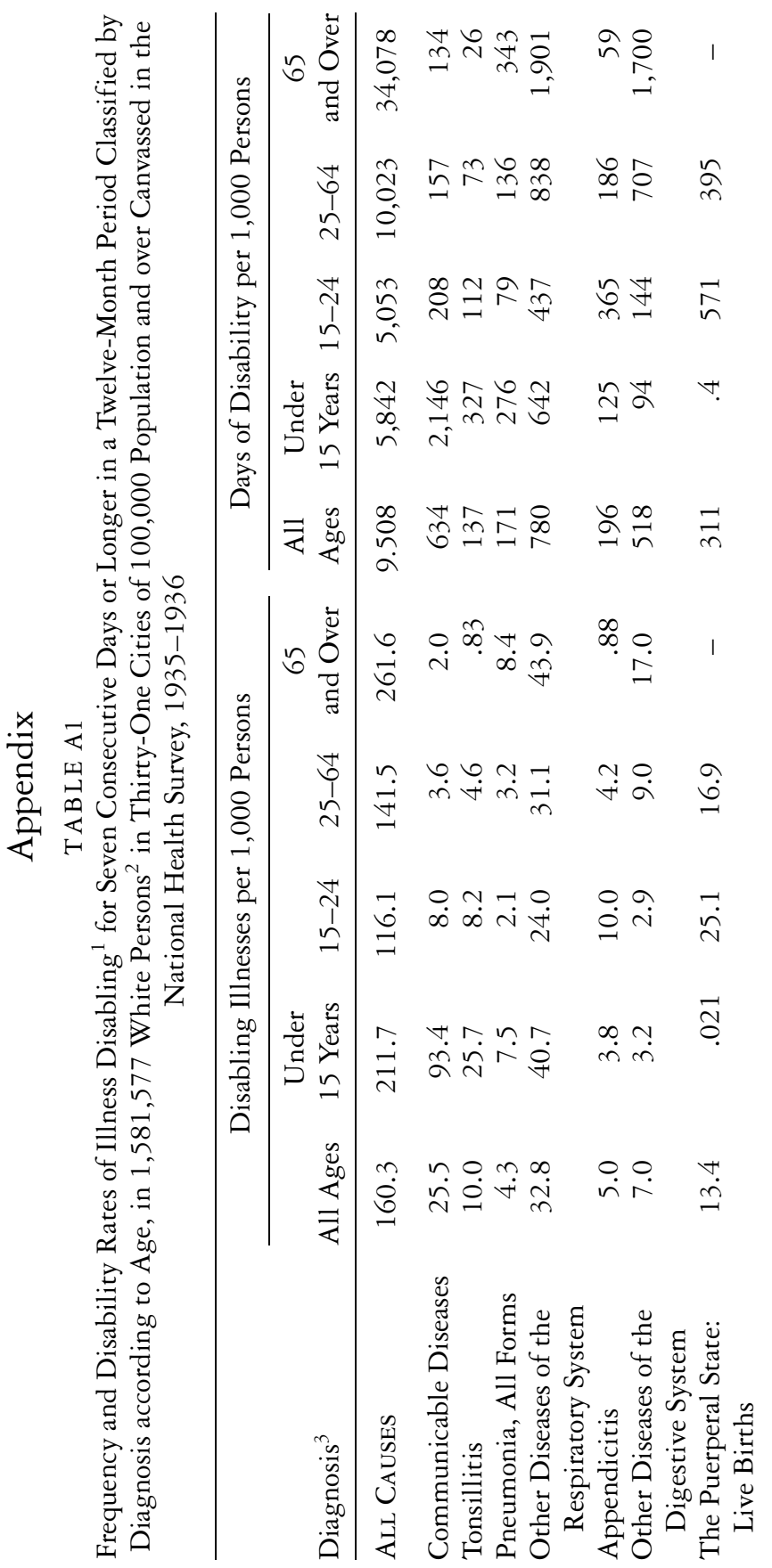




\begin{tabular}{|c|c|c|}
\hline$\infty$ & 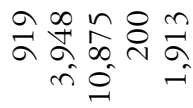 & 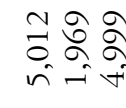 \\
\hline i & 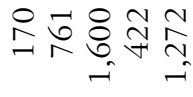 & $\stackrel{N}{\infty} \approx \stackrel{\infty}{\approx}$ \\
\hline$\widetilde{6}$ & $\begin{aligned} \sigma & =0 \stackrel{n}{n} \underset{m}{m} \\
& =\end{aligned}$ & 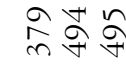 \\
\hline$\infty$ & $v \vec{\infty} \underset{\sim}{\stackrel{\sim}{\sim}} \vec{a} \underset{\forall}{\sharp}$ & $\begin{array}{lll}0 & \Downarrow & \sim \\
N & \sim & N\end{array}$ \\
\hline
\end{tabular}

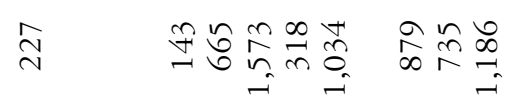

$\stackrel{n}{r} \quad$ ํํำ

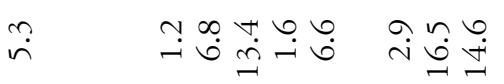

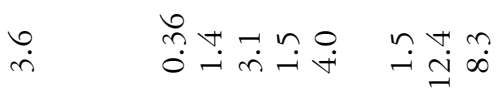

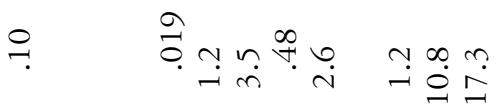

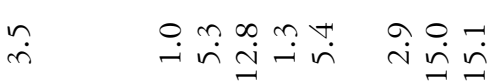

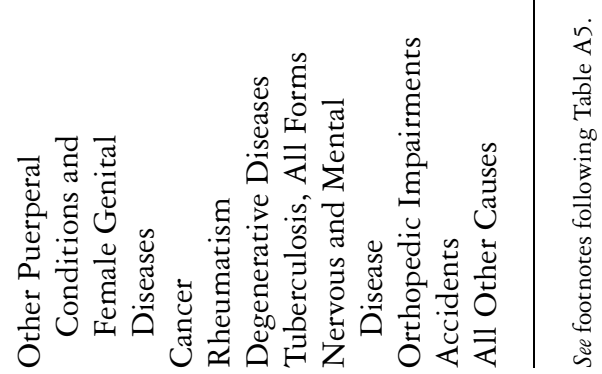




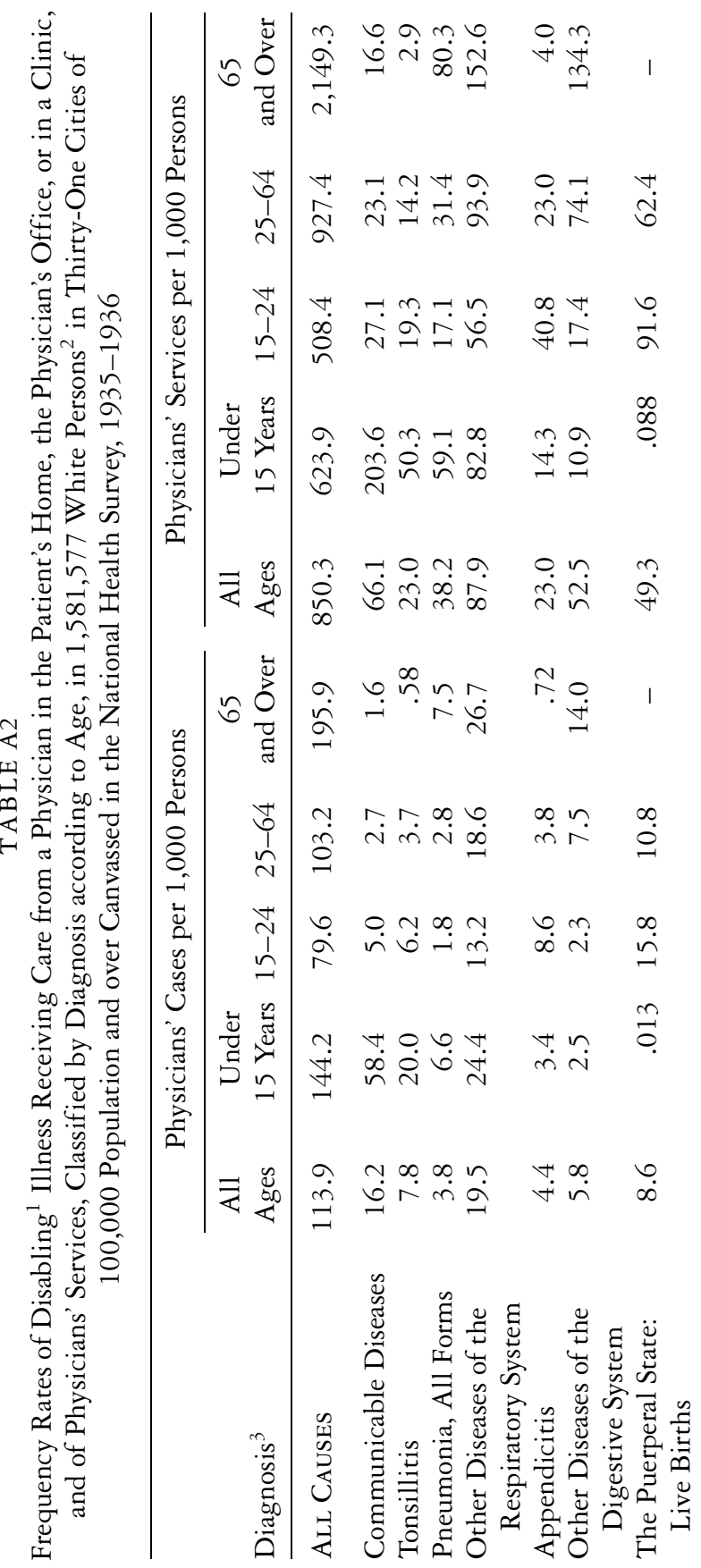




\begin{tabular}{|c|c|c|}
\hline$\stackrel{r}{r}$ & 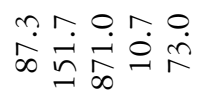 & 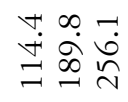 \\
\hline 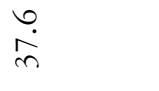 & 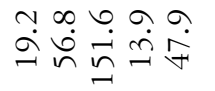 & 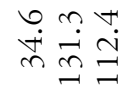 \\
\hline $\begin{array}{r}\stackrel{r}{v} \\
\stackrel{v}{v}\end{array}$ & 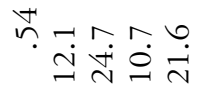 & 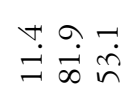 \\
\hline $\bar{\sigma}$ & 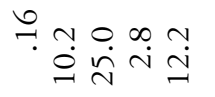 & 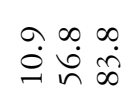 \\
\hline $\begin{array}{l}\text { ֻே } \\
\stackrel{+}{v}\end{array}$ & 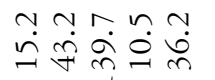 & $\begin{array}{lll}\Downarrow & n & 0 \\
\grave{\lambda} & \infty & 0\end{array}$ \\
\hline$\hat{\sigma}$ & 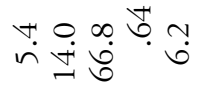 & $\stackrel{\infty}{\sim} \underset{0}{\sim}$ \\
\hline$\stackrel{\forall}{\forall}$ & 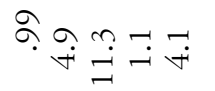 & 艺 \\
\hline$\stackrel{0}{\dot{r}}$ & 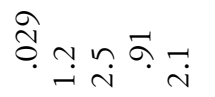 & $\stackrel{n}{r} \ddot{a} \dot{b}$ \\
\hline $\begin{array}{l}\infty \\
\infty \\
0\end{array}$ & $\vec{\sigma} \underset{\sim}{\sigma} \stackrel{\infty}{\sim} \stackrel{\infty}{\sim} \stackrel{\sim}{\sim}$ & 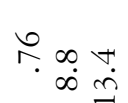 \\
\hline 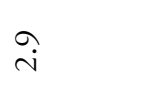 & $\stackrel{n}{\infty} \underset{n}{\infty} \stackrel{\infty}{\infty} \stackrel{n}{n}$ & 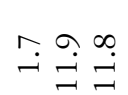 \\
\hline 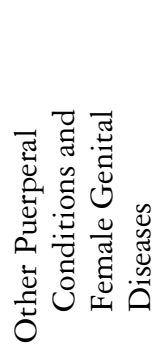 & 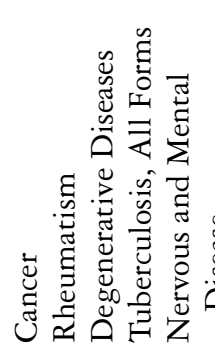 & 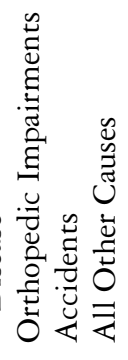 \\
\hline
\end{tabular}




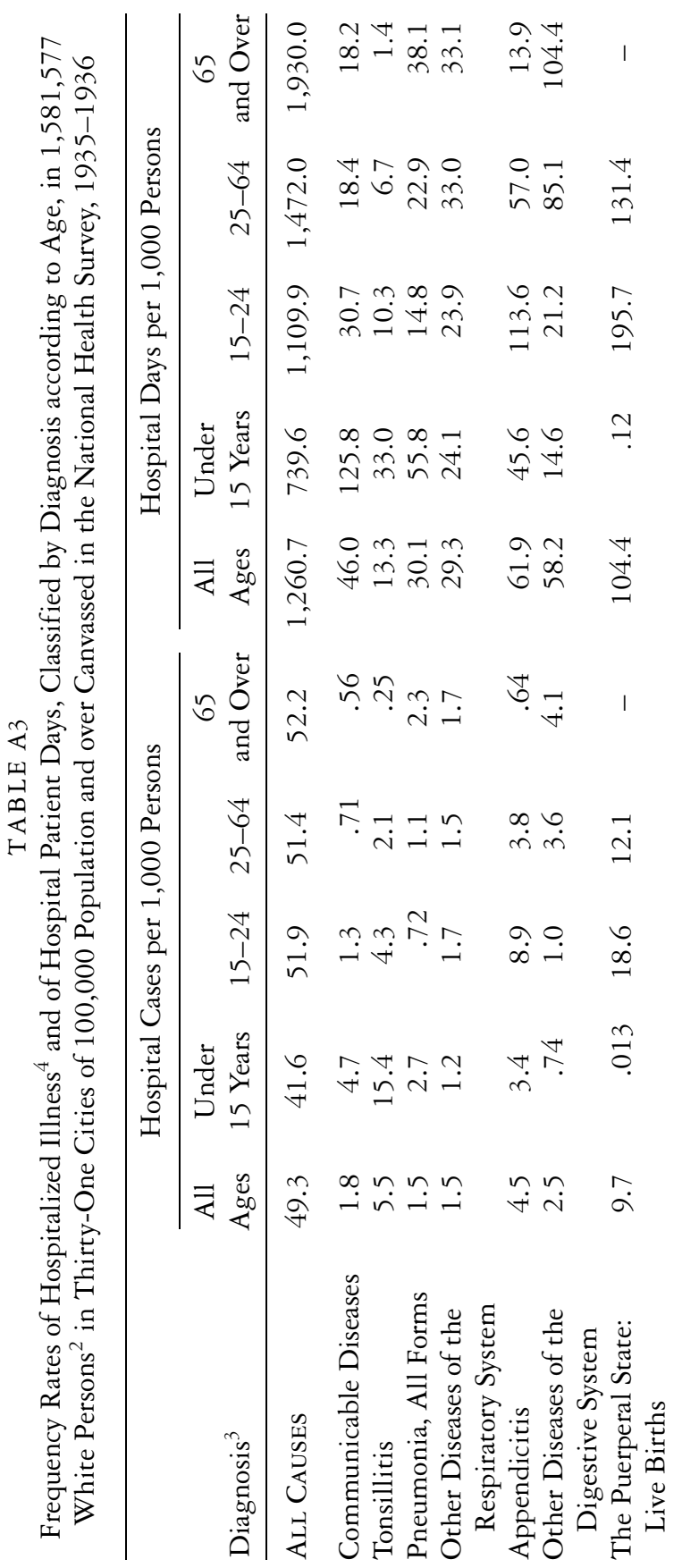




\begin{tabular}{|c|c|c|}
\hline$\stackrel{\infty}{r}$ & 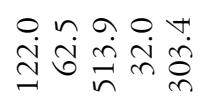 & 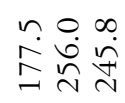 \\
\hline$\ddot{\circ}$ & 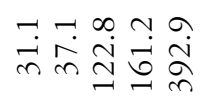 & 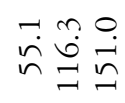 \\
\hline $\begin{array}{l}\infty \\
\stackrel{\infty}{v}\end{array}$ & 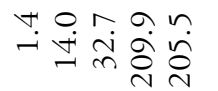 & $\begin{array}{l}0 \\
\hat{n} \\
\dot{n}\end{array}$ \\
\hline$\tilde{6}$ & 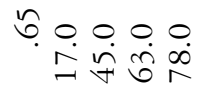 & 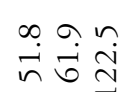 \\
\hline$\stackrel{⿱ 亠 凶}{m}$ & 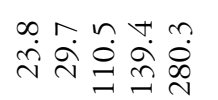 & 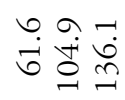 \\
\hline$\stackrel{Q}{\forall}$ & 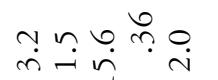 & $\because \stackrel{0}{\ddots} \stackrel{0}{\infty}$ \\
\hline$\stackrel{n}{n}$ & $\stackrel{\infty}{\infty} \underset{+}{\circ} \underset{\sim}{\sim}$ & $\stackrel{9}{r} \underset{n}{n}$ \\
\hline$\stackrel{\vartheta}{-}$ & 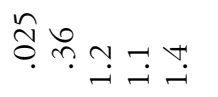 & $\underset{n}{n} \tilde{n}$ \\
\hline$\hat{n}$ & $\stackrel{n}{\sigma} \approx n$ そฺ & 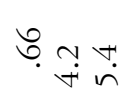 \\
\hline$\ddot{\sim}$ & 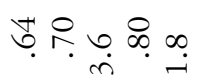 & 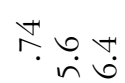 \\
\hline 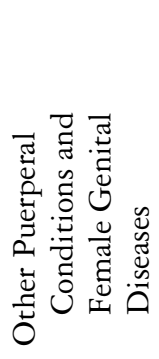 & 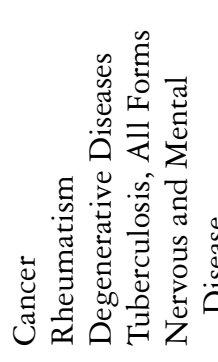 & 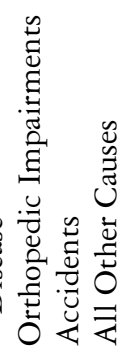 \\
\hline
\end{tabular}




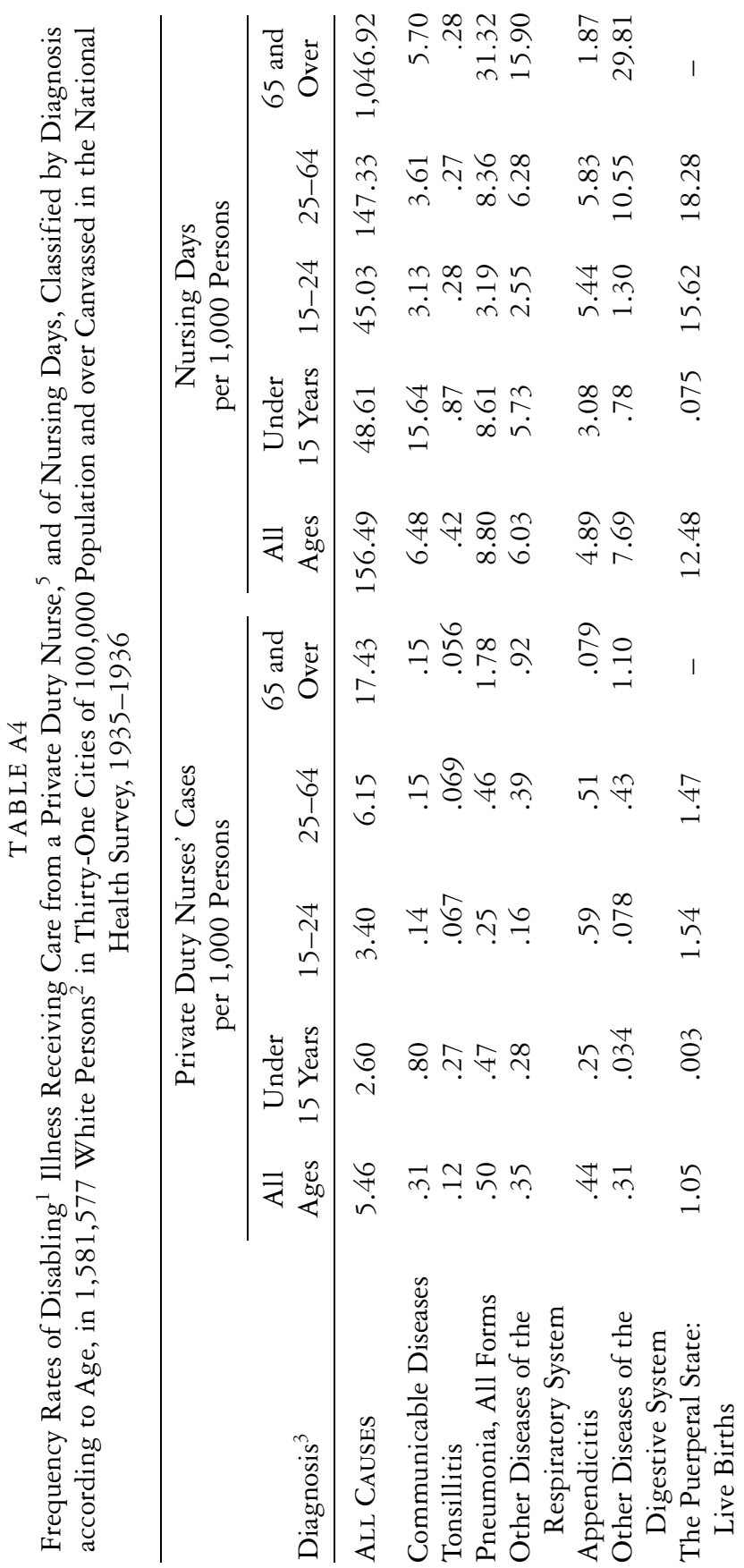




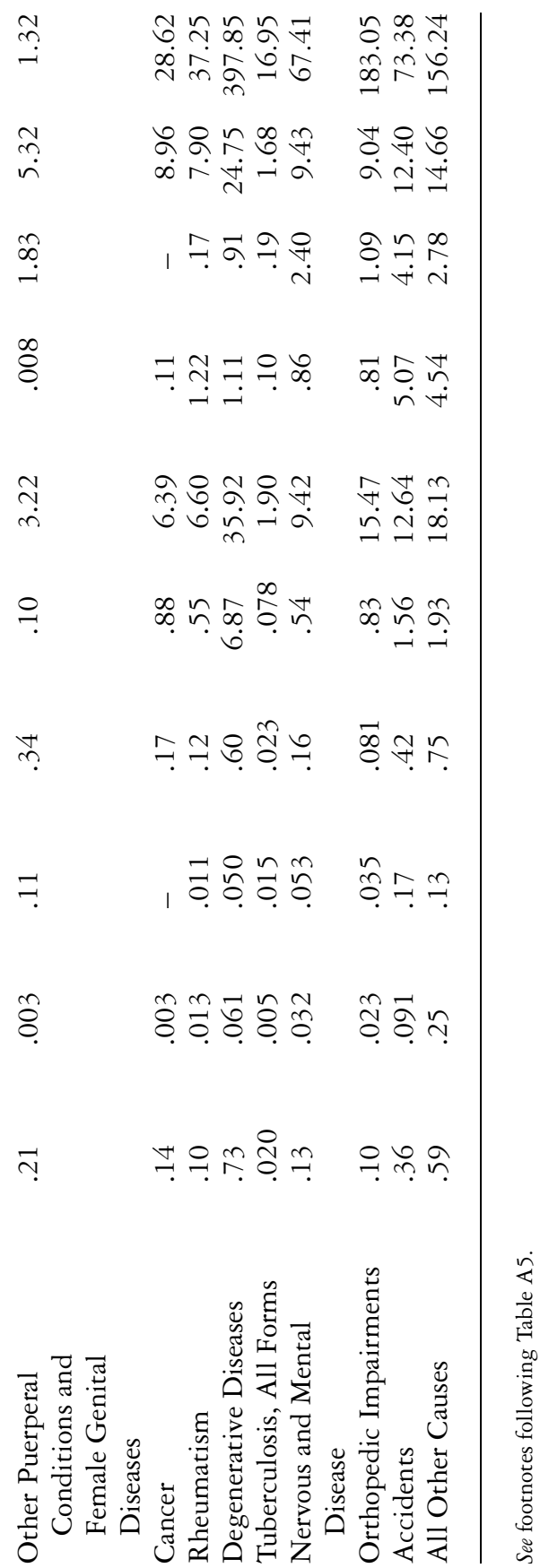




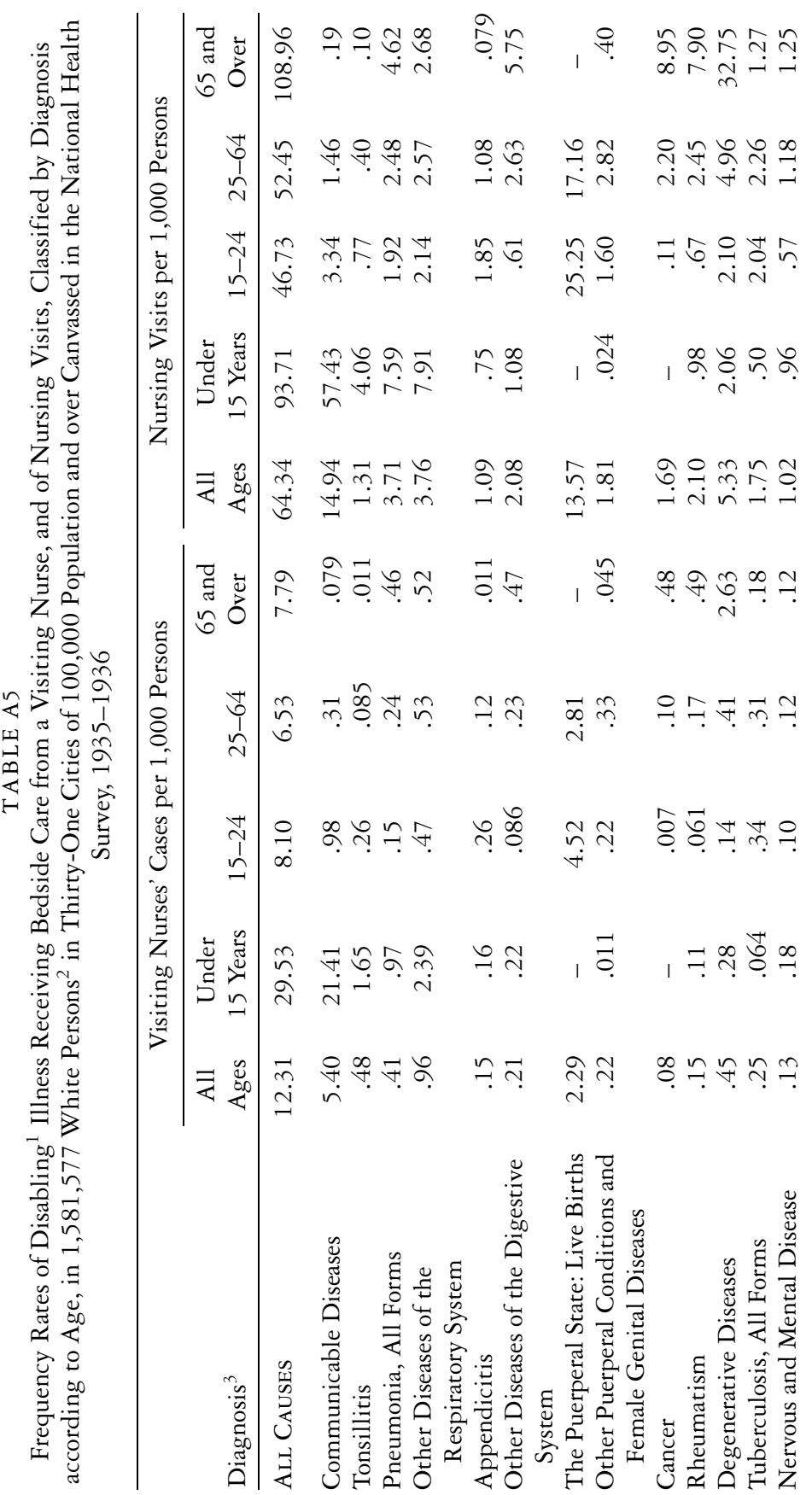




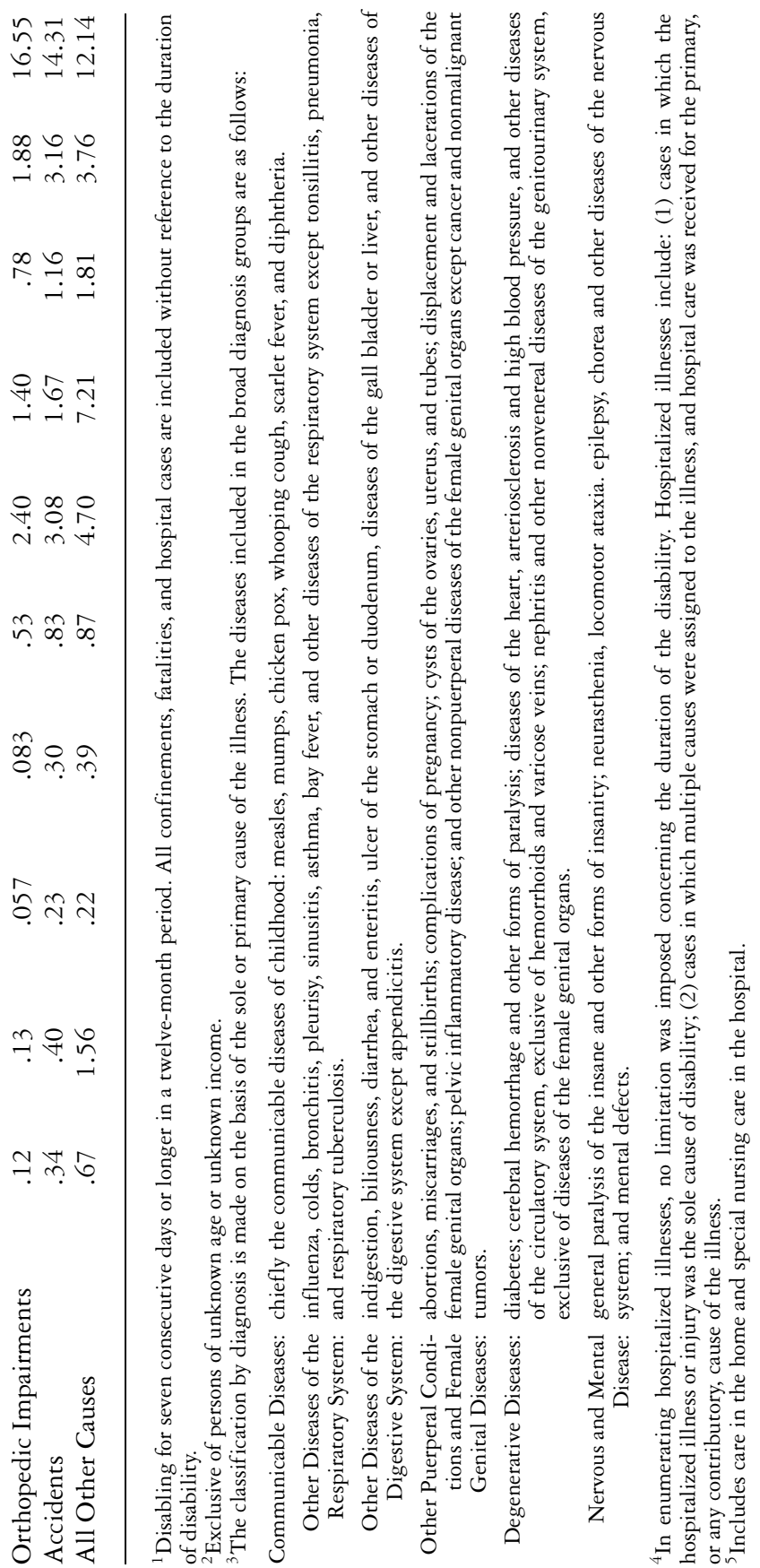




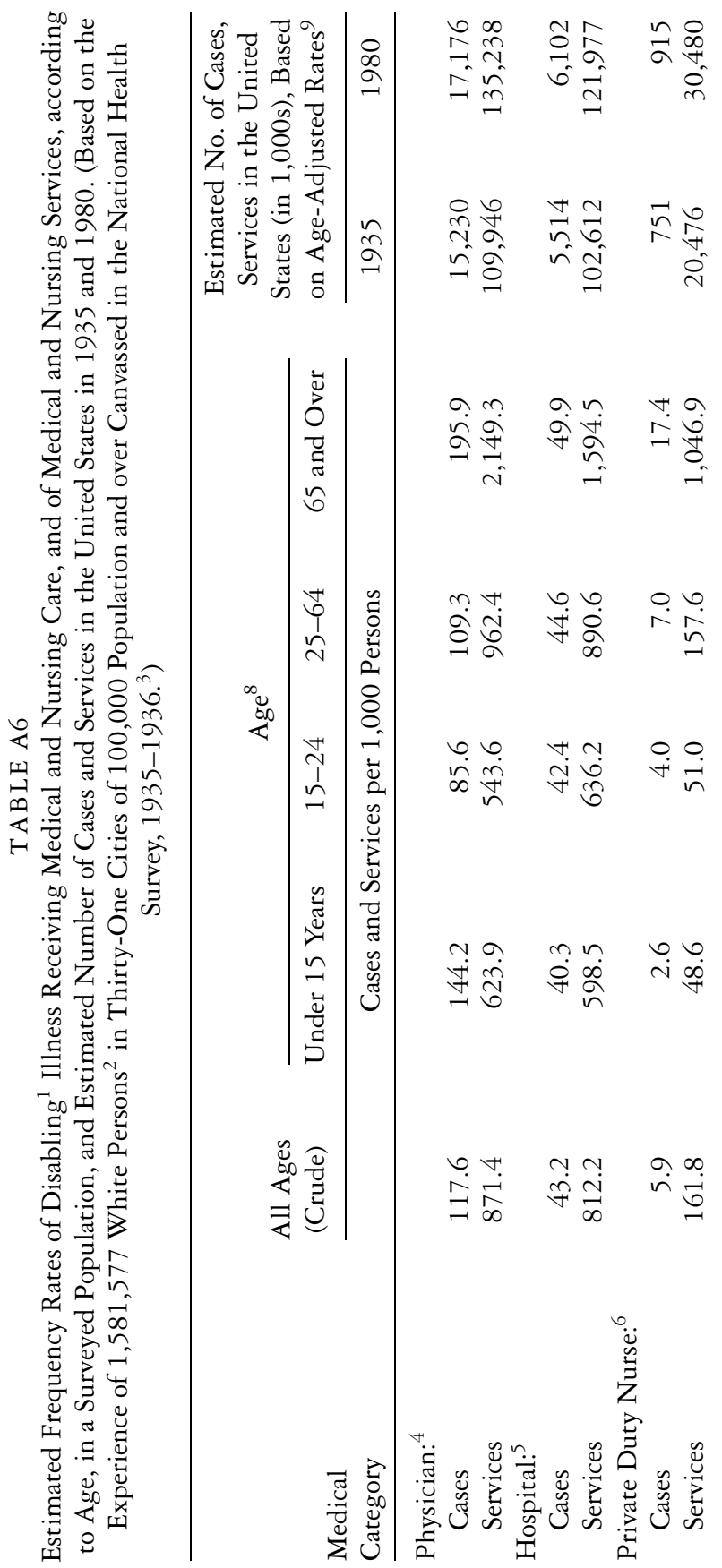




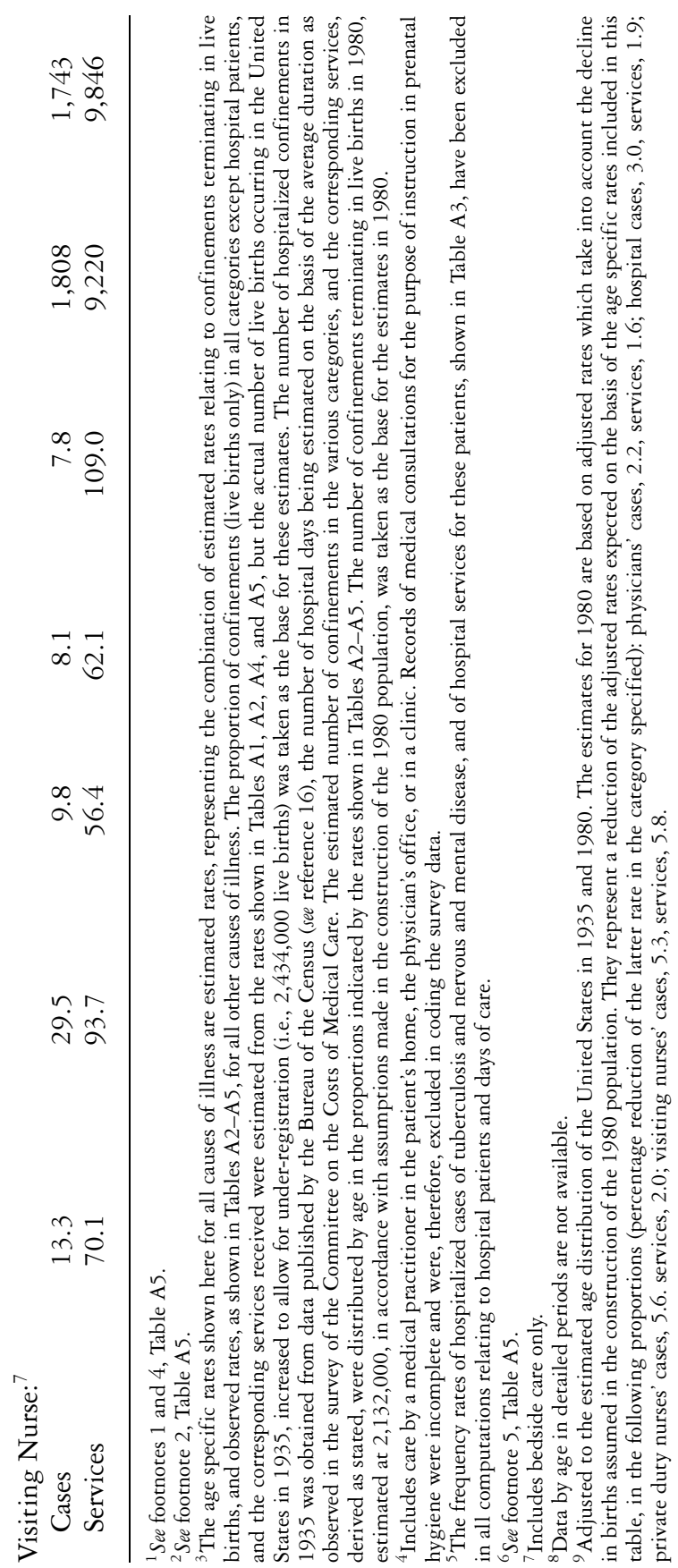




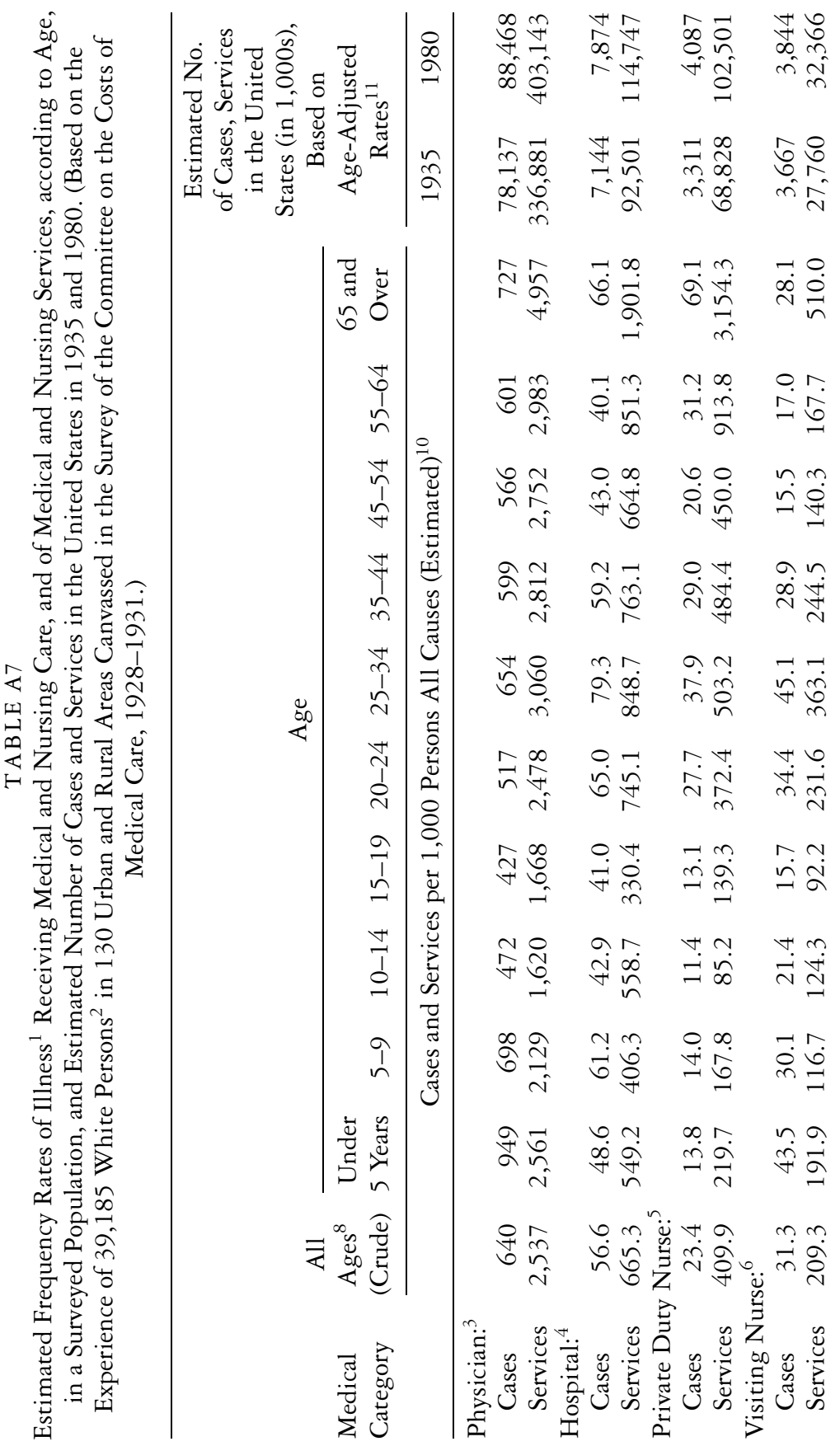




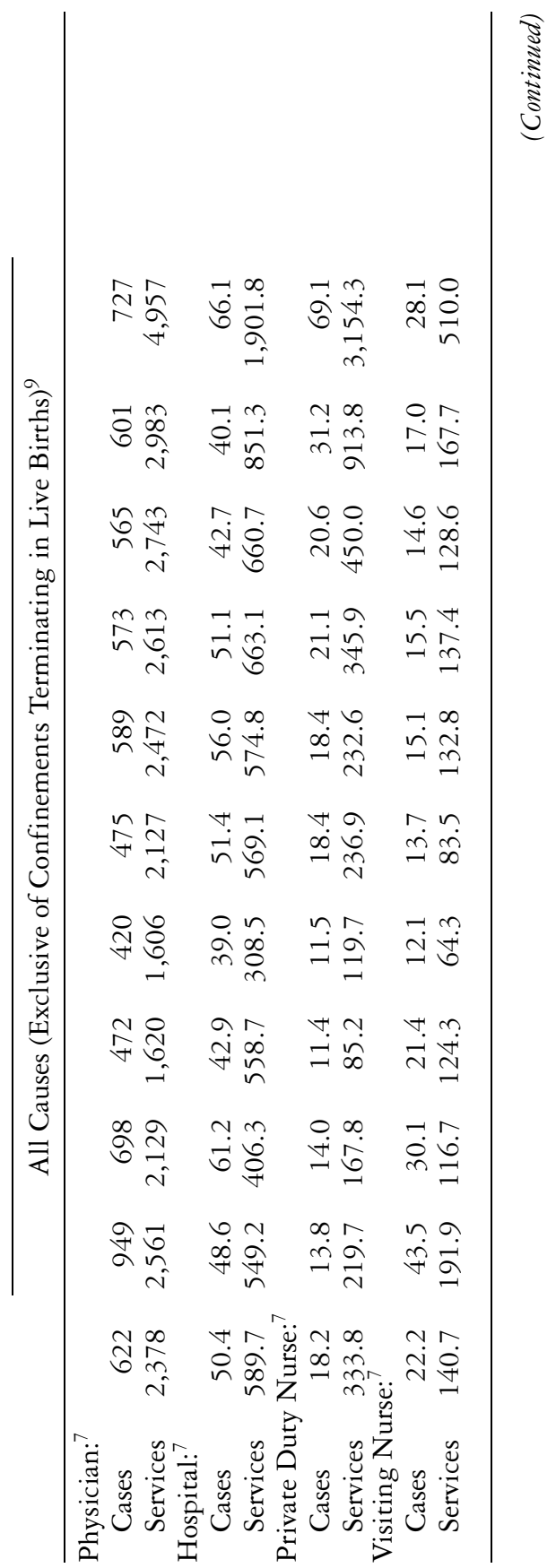




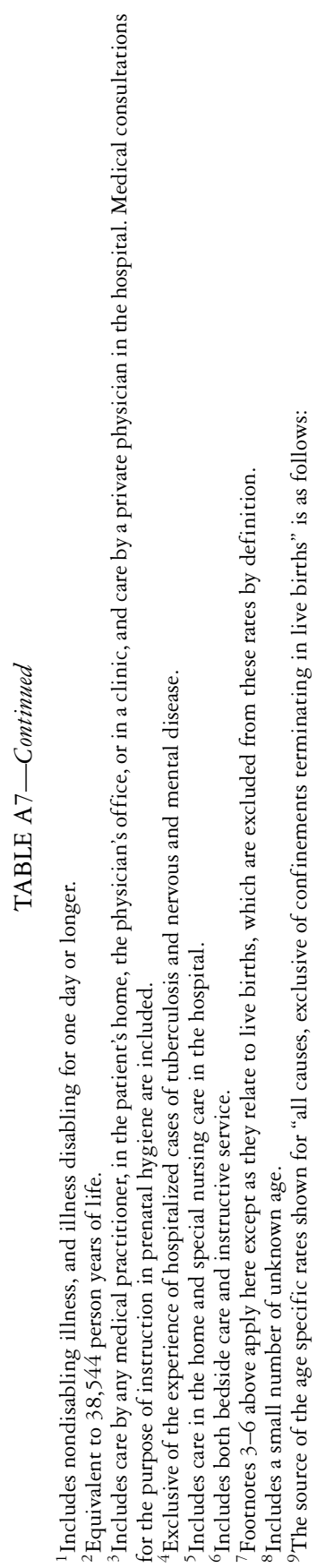

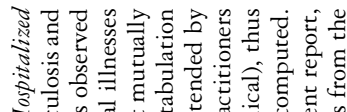

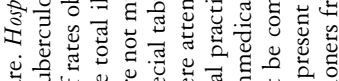

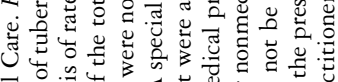

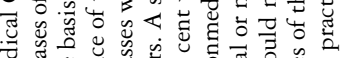

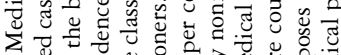

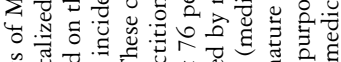

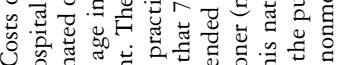

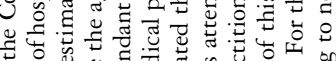

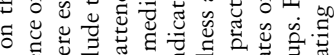

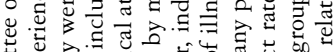

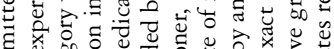

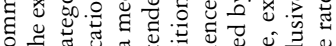
U.

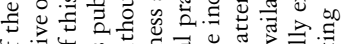

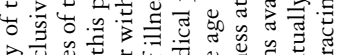

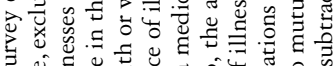
क ज्ञ

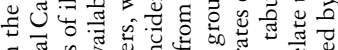

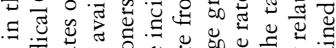

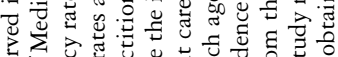

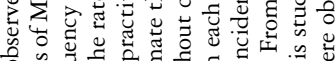

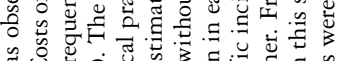

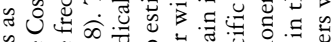

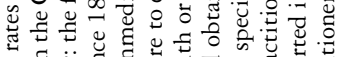

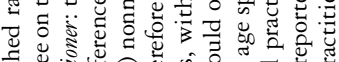

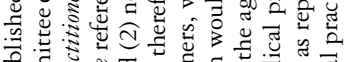

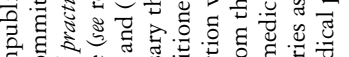

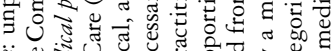

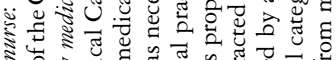

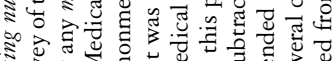

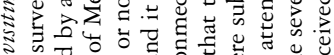

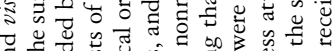

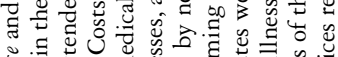

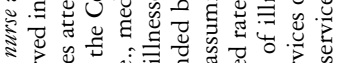

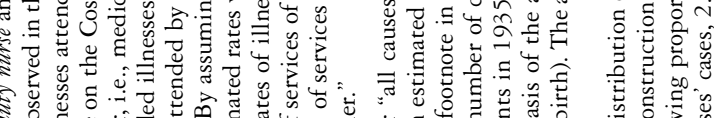

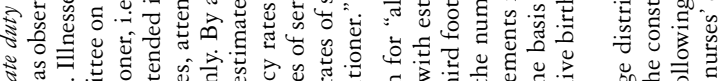
₹

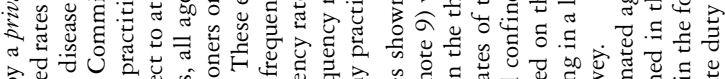
B.

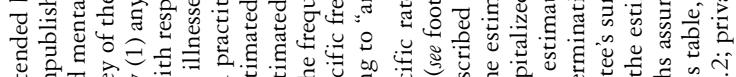

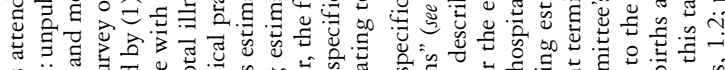

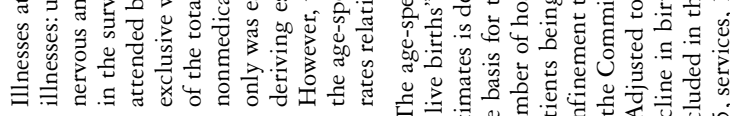

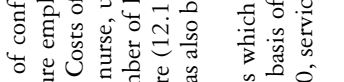

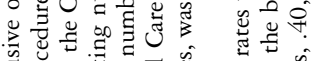

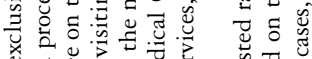

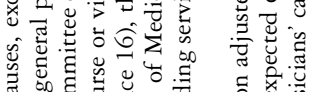

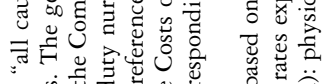

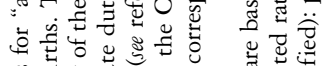

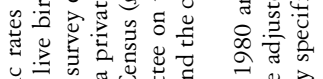
岛. 员.

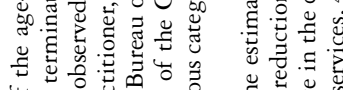

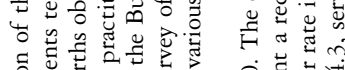

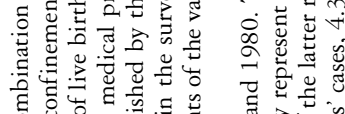

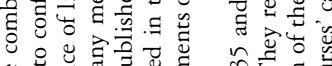

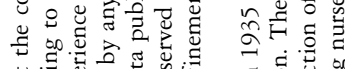

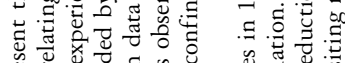

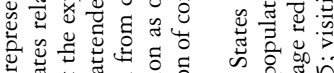

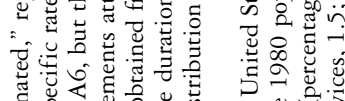

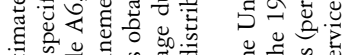

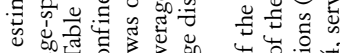
1.

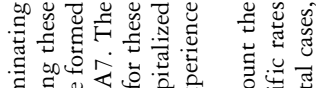

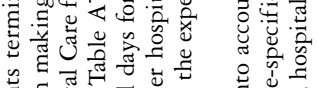

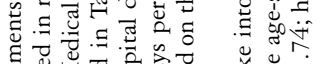

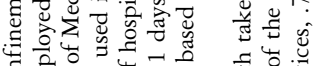

